\title{
Improving Risk Sharing and Borrower Incentives in Mortgage Design
}

\author{
Yuchen Mei, Phelim Boyle and Johnny Siu-Hang Li
}

\begin{abstract}
In a traditional fixed rate mortgage, the borrower pays a fixed amount each period regardless of the value of the mortgaged property. One problem with this contract is that the borrower is less willing to pay when the house value falls. This was clearly seen in the 2008 financial crisis and its aftermath when mortgage default rates and foreclosures skyrocketed as the housing market crashed. A more efficient contract design should link payments to house prices so that the borrower's incentive to pay is not undermined by a decline in property value. In addition this design can save the lender the deadweight foreclosure costs. In this paper we examine two proposed index linked mortgages which have this risk sharing feature. We analyze the effect of both designs on borrower incentives in a multi-period setting.
\end{abstract}

\section{Introduction}

The 2008-2009 financial crisis had a very serious impact on financial markets as well as on the real economy. The causes of the crisis have been widely discussed and documented (see, e.g., FCIC [35], Barth et al. [6], Hellwig [24], Lo [29] and Mian and Sufi [31]). It is generally agreed that one of the triggering events was the collapse of the subprime mortgage market. These mortgages were associated with high risk borrowers and their expansion in the early 2000's fuelled a rapid increase in house prices. Many of these loans were securitized and sold to investors. When the housing bubble began to collapse many of the borrowers defaulted and losses were transmitted and magnified across the financial system, causing a credit crisis. The crisis soon spilled over the whole economy and resulted in an economic recession.

During the crisis the US house prices fell by one third causing a decline of $\$ 5.6$ trillion of household net worth. Defaults and foreclosures rose dramatically. According the FCIC [35], by late $20099.7 \%$ of mortgage loans were seriously delinquent. In particular, the delinquency rate for subprime adjustable rate mortgages was above $40 \%$. Although subprime loans were especially vulnerable to negative house price shocks, non-subprime loans were also severely impacted. For example, prime fixed rate mortgage (FRM) loans were considered the least risky and had a historical delinquency rate below 1\%. Their delinquency rate rose to $5 \%$ in 2009 .

Ambrose and Buttimer [2] argue that the excessive number of defaults on standard mortgages during the crisis and its aftermath are indicative of an inefficient contract. They argue 
that current mortgage designs are flawed since the threat of foreclosure is not an effective deterrent to default when house price declines are large enough. Defaults and foreclosures impose costs on borrowers and lenders. The borrower loses his/her home and his/her credit rating is impaired. Foreclosures represent significant deadweight costs for the lender. To reduce these costs, Ambrose and Buttimer [2] propose new mortgage designs that can better capture house price risk. If new designs can reduce the number of defaults and the associated deadweight costs, then it should be possible to improve the welfare of both borrowers and lenders. The main goal of this paper is to study alternative mortgage designs that improve house price risk sharing and reduce defaults.

To illustrate the main idea we take the fixed rate mortgage (FRM) as an example since it has been the most popular product in the US mortgage market for decades. Under a standard FRM, the borrower repays the loan by level monthly payments. The amount of the regular payment is determined at the outset by amortizing the loan over its outstanding term at the fixed contract rate. The most common amortization period in the US is 30 years. The monthly payments are fixed and do not depend on the level of prevailing interest rates or house prices. However when the ruling mortgage rate falls below the current contract rate, the borrower can pay off the existing loan and take out a new one with a lower rate and lower monthly payments. This is a valuable option to the borrower since he/she can exercise it without any penalty.

The borrower also has an option to default. At inception the value of the house exceeds the amount of the loan because of the down payment. As time passes the amount of the outstanding balance under a FRM declines; very slowly at first and then more quickly reaching zero at the end of the contract. If house prices decline it is possible for the value of the amount owing on the loan to exceed the value of the collateral property. In this case the homeowner is said to have negative equity in the home and this provides an incentive for the homeowner to default. If the borrower fails to make the payments, the lender assumes ownership and can sell the house to recover the amount owed on the loan and associated costs. Hence the lender is protected against house price risk to the extent that the collateral property is worth more than the amount owed plus potential costs. The FCIC [35] reported that in 2009, $22.5 \%$ of the households with mortgages in the US had negative equity.

Many empirical studies confirm that negative equity is significantly and positively associated with default after controlling for other factors (Deng et al. [15], Goodman [21], Foote et al. [18], Elul et al. [16]). If the borrower loses his/her job or has a cut in income we would expect his/her incentives to default to intensify. This is confirmed by the empirical evidence which shows that the association between negative equity and default is stronger when a borrower is also financially constrained (Elul et al. [16], Gerardi et al [19]). A particular type of default arising from negative equity is 'strategic default' (Guiso et al. [22], Bradley et al. [8], Bhutta et al. [7]), which occurs when a borrower is in a negative equity position but still capable of making the mortgage payments. Strategic default can be seen as an explicit exercise of the default option.

As pointed out by Ambrose and Buttimer [2], the foreclosure process following default 
imposes substantial costs on both the borrower and the lender. The borrower has to search for a new residence and bear any cost associated with relocation. The switch from owning a house to rent may also reduce his/her living standard. The borrower's credit rating could be degraded, which raises his/her cost of financing in the future. In addition to these explicit costs, there are psychological costs arising from morality and social stigma.

The various foreclosure costs to the lender are described in detail by Brueggeman and Fisher [9]. If the borrower defaults with negative equity, the lender loses the difference between the outstanding loan balance and the value of the property. In addition, foreclosed properties are typically sold at a discount, which Campbell et al. [12] estimate to be $27 \%$ on average. This discount may be due to urgency of sale and/or vandalism. Combining these costs, the lender's net loss given default may amount to a significant proportion of the outstanding loan balance. Qi and Yang [33] further show that this loss tends to increase in distressed housing markets.

Studies have also shown that foreclosure has negative externalities to society (Andritzky [4]). In particular, foreclosure reduces the prices of neighboring properties (Campbell et al. [12], Gerardi et al. [20] and Anenberg and Kung [5]). Anenberg and Kung [5] use listing data to show that properties located close to a foreclosed property sell at a $1.6 \%$ discount on average. Mian et al. [32] use state foreclosure laws as an instrument to exploit the causal effect of foreclosures on house prices. They find that foreclosures account for 20-30\% of the reduction in house prices and lead to reduced household consumption.

The lender is exposed to house price risk because the borrower's incentive to default is influenced by house prices. There are four approaches for the lender to manage the risk. These are mortgage default insurance, diversification, ex post modification and ex ante contracting. We discuss these in turn. In the first approach, the borrower pays the premium for the insurance which protects the lender in the case of default. Mortgage insurance is often mandatory for low down payment mortgages. This insurance is designed to transfer some of the default risk to a third party. During the crisis both private and public mortgage insurers experienced severe financial difficulties. The Federal Housing Administration, the largest public mortgage insurer in the US, reported a negative 13.5 billion of economic net worth in 2012. ${ }^{1}$ The loss ratio of the US private mortgage insurers was above $200 \%$ in 2008 and $2009,{ }^{2}$ and two of them were put under receivership in 2011.

The second approach is to diversify business across different geographical areas. This approach is also used by mortgage insurers. However its effectiveness was reduced during the crisis. Cotter et al. [14] find that the level of housing market integration increased during the periods of boom and bust, suggesting "substantial limitations to geographic diversification as a strategy for portfolio risk mitigation".

The third approach is to rely on ex post loan modifications or foreclosure alternatives. The lender makes contract modifications to reach some agreement with the borrower who has

\footnotetext{
${ }^{1}$ The FHA annual report for fiscal year 2014 is available at http://portal.hud.gov/hudportal/HUD?src= /fhammifrpt.

${ }^{2}$ Source: The Mortgage Insurance Companies of America (MICA) 2012-2013 Fact Book and Member Directory. MICA is recently replaced by U.S. Mortgage Insurers (USMI).
} 
already defaulted so that the cost to the lender is minimized. However, such negotiations are costly and may fail (Ambrose and Capone [3]). In addition, securitization and asymmetric information may have made negotiations more difficult and loan modifications less attractive to lenders (FCIC [35], Adelino et al. [1], Foote et al. [17]).

The fourth approach to manage house price risk is to redesign the mortgage contract. We will show later that this approach improves risk sharing and reduces the borrower's incentives to default. In this paper, we consider two risk sharing designs that have been proposed in the literature. The key idea is to reduce the borrower's payment when the value of the mortgaged property is low. Since individual house prices are not readily observable without expensive ongoing appraisals, the borrower's payments are linked to a suitable property index rather than the exact value of the mortgaged property. This type of mortgage contract is called a property index linked mortgage (PILM).

In a PILM, the mortgage payments and balance are linked to an index that is based on the local real estate market. The mortgage payments and loan balances are reduced when the index falls below a certain level. This mechanism can reduce the homeowners' incentives to default by reducing the amounts of payments and negative equity at times when the housing market performs badly. Our first PILM design is based on the adjustable balance mortgage proposed by Ambrose and Buttimer [2], and the second is based on the continuous workout mortgage proposed by Shiller et al. [34] and the shared-responsibility mortgage proposed by Mian and Sufi [31]. Besides its unique loan adjustment and house price risk sharing mechanisms, the PILM is also expected to have a lower premium for default insurance than the standard FRM.

The contribution of this paper is to analyze these designs from the borrower's perspective. We emphasize the borrower's perspective since it is the borrower who makes the decision to default, prepay or continue. We assume that the borrower makes mortgage related decisions to maximize his/her lifetime utility of consumption, and that the lender's profit depends on these decisions. This type of model has been used previously by Campbell and Cocco [10, 11] to study mortgage choice and mortgage default. We use a discrete-time model under which the borrower has three choices at each time point. He/she can continue to pay the mortgage, pay off the existing loan and refinance with a new mortgage, or default on the existing mortgage. In our model, the optimal decision depends on several state variables that describe the conditions faced by the borrower. We determine the borrower's optimal strategy and this permits us to measure the default incentives and economic consequences of different mortgage designs.

In our baseline case the PILM borrowers have weaker incentives to default than the FRM borrower and their welfare is higher. The PILM lenders can expect on average no lower present value of cash flows than the FRM lender, even though all lenders charge the same contract rate. These results imply that the cost of loan adjustments is fully covered by the savings of foreclosure costs arising from a lower default probability, and hence PILMs could be Pareto improving relative to the standard FRM. Comparing the two PILM designs, we find that the second has a lower default probability and derives higher welfare for both the borrower and lender. 
The PILM borrowers' lower propensity to default and higher welfare are maintained in most of the cases where alternative parameter values are considered, but the PILM lenders' welfare could be higher or lower. We also find that a lower default probability is most likely associated with higher borrower welfare when comparing different cases for each contract. Nevertheless, if the FRM borrower has a low propensity to default, the reduction in default probability brought by PILM loan adjustments may not be sufficient to yield large enough reductions in foreclosure costs to cover the cost of loan adjustments. We also demonstrate that the welfare allocation between the borrower and the lender can be adjusted through some contract parameters, such as mortgage rate and loan adjustment intensity.

The rest of this paper is organized as follows. Section 2 defines the three contracts of interest: one traditional FRM and two different PILMs. Section 3 establishes the multi-period model and states the assumptions needed to solve the optimization problem. The optimal decision rules determine borrowers' behaviour, which is described in Section 4. We use simulations to estimate probability of default and welfare. Section 5 provides some robustness checks by varying certain parameters. The last section concludes with the main findings and limitations.

\section{Contracts}

This section describes the three mortgage contracts under consideration. We first define the FRM contract which is standard in the current mortgage market. The payment under a FRM is independent of the value of the mortgaged property. Next we define two different designs of PILM contracts under which loan payments and balances are reduced when the property value declines (significantly). The differences between the two PILMs are demonstrated by comparing their payments and outstanding balances under a hypothetical scenario.

In what follows, we use $H_{t}, M_{t}$ and $B_{t}$ to denote the time- $t$ values of the mortgaged property, the mortgage payment and the outstanding loan balance, respectively. The formulas for $M_{t}$ and $B_{t}$ presented below are derived under the assumption that the borrower does not prepay prior to time $T$, the term of the mortgage.

\subsection{Fixed Rate Mortgage (FRM)}

In a FRM contract, the loan is fully amortized at origination such that the borrower repays the same amount at each time point. The mortgage payment due at time $t$ is given by

$$
M_{t}=\alpha H_{0} \frac{\mathrm{ER}_{0}}{1-\left(1+\mathrm{ER}_{0}\right)^{-T}}, \quad t=1, \ldots, T
$$

where $\alpha$ is the initial loan-to-value (LTV) ratio and $\mathrm{ER}_{0}$ is the mortgage contract rate for a FRM contract originated at $t=0$. Note that for a FRM contract, the value of $M_{t}$ is determined at origination and does not change over time. The amount of the outstanding balance declines to zero over the term of the loan from the initial amount of $\alpha H_{0}$. It is a deterministic function of time and thus does not depend on the current property value. There is no prepayment penalty. 


\subsection{Property Index Linked Mortgage: Version One (PILM1)}

In a PILM1 contract the outstanding balance on the mortgage is adjusted to reflect house price changes as measured by an appropriate property index. Immediately after the mortgage payment at time $t$, the unpaid principal balance is adjusted so that the current LTV (calculated using the house price implied by the property index) does not exceed the target LTV. If the price decline is severe enough the loan balance is adjusted downwards. The mortgage payment then drops as it is based on the revised loan balance. In this way the borrower's payment goes down when there is a severe house price decline. On the other hand if house prices rise, the loan balance may be adjusted upwards, but the post-adjustment balance is capped by an amount calculated at loan origination. ${ }^{3}$

We first specify the reference balance and payment. The reference balance is the balance the borrower faces when the loan is not adjusted, and it also represents the upper bound of post-adjustment loan balance if an adjustment is triggered. The reference payment serves a similar purpose. Let $U_{t}$ be the time- $t$ reference balance and $\bar{M}$ be the (constant) reference payment. The values of $U_{t}$ and $\bar{M}$ are are determined at loan origination by amortizing the initial loan amount over the loan term with contract rate $\mathrm{ER}_{0}+\mathrm{RS} 1$, where $\mathrm{RS} 1$ is the rate spread of PILM1 over the corresponding FRM; that is,

$$
U_{t}=\left\{\begin{array}{ll}
\alpha H_{0}, & t=0 \\
U_{t-1}\left(1+\mathrm{ER}_{0}+\mathrm{RS} 1\right)-\bar{M}, & t=1, \ldots, T
\end{array},\right.
$$

and

$$
\bar{M}=\alpha H_{0} \frac{\mathrm{ER}_{0}+\mathrm{RS} 1}{1-\left(1+\mathrm{ER}_{0}+\mathrm{RS} 1\right)^{-T}} .
$$

During the term of the loan, the actual loan balance $B_{t}$ may deviate from $U_{t}$ due to adjustments that ensure the target LTV, $0<\bar{\alpha}<1$, is maintained. Mathematically, the postadjustment loan balance of the PILM1 at time $t$ can be expressed as

$$
B_{t}=\min \left(\bar{\alpha} H_{0} \frac{I_{t}}{I_{0}}, U_{t}\right), \quad t=1, \ldots, T
$$

For simplicity, we assume that there is no basis risk, so that the actual property value is always identical to the property value implied by the index throughout the term of the mortgage; that is,

$$
H_{t}=\frac{I_{t}}{I_{0}} H_{0}, \quad 0 \leq t \leq T .
$$

Under this assumption, the formula for calculating the post-adjustment loan balance can be simplified to

$$
B_{t}=\min \left(\bar{\alpha} H_{t}, U_{t}\right), \quad t=1, \ldots, T
$$

We refer readers to Ambrose and Buttimer [2] for a qualitative discussion on basis risk and to our parallel study [30] for a possible method to quantify the effect of basis risk on lenders' cash

\footnotetext{
${ }^{3}$ The advantages of capping the post-adjustment loan balance is discussed by Ambrose and Buttimer [2].
} 
flows.

The payment due at the end of the next period is then calculated by amortizing $B_{t}$ over the remaining term of the loan:

$$
M_{t+1}=B_{t} \frac{\mathrm{ER}_{0}+\mathrm{RS} 1}{1-\left(1+\mathrm{ER}_{0}+\mathrm{RS} 1\right)^{t-T}}, \quad t=1, \ldots, T-1
$$

Note that $M_{1}=\bar{M}$ because by design a loan adjustment at $t=0$ is impossible.

Should the borrower choose to prepay at time $t$, he/she would be subject to a prepayment penalty $\mathrm{PP}_{t}$ that equals a fraction of the difference between $U_{t}$ and $B_{t}$; that is,

$$
\mathrm{PP}_{t}=\operatorname{PRE} 1\left(U_{t}-B_{t}\right), \quad t=1, \ldots, T-1
$$

where $0 \leq \mathrm{PRE} 1 \leq 1$ is a constant parameter. ${ }^{4}$ Upon prepayment the sum of the postadjustment balance $B_{t}$ and the prepayment penalty $\mathrm{PP}_{t}$ becomes the initial amount of the new loan. Note that if an adjustment is not triggered at time $t$, then $B_{t}=U_{t}$ and hence the prepayment penalty is zero.

\subsection{Property Index Linked Mortgage: Version Two (PILM2)}

Under a PILM2 contract the mortgage payment is reduced if there is a decline in the house price relative to its value at loan origination. The mechanism used in this case is different from that used in PILM1 contracts. In a PILM1 the loan balance is adjusted to reflect house price declines and this induces a reduction in the mortgage payments, but in a PILM2 contract the mortgage payment is adjusted first and the outstanding loan balance is computed based on the revised mortgage payment. As with PILM1 contracts, the loan adjustments under PILM2 contracts are capped and are linked to a suitable property index. We also assume here that there is no basis risk.

Let us consider a PILM2 with a rate spread of RS2 over the corresponding FRM and thus a contract rate of $\mathrm{ER}_{0}+\mathrm{RS} 2$. Its reference payment and time- $t$ reference balance are respectively given by

$$
\bar{M}=\alpha H_{0} \frac{\mathrm{ER}_{0}+\mathrm{RS} 2}{1-\left(1+\mathrm{ER}_{0}+\mathrm{RS} 2\right)^{-T}}
$$

and

$$
U_{t}=\left\{\begin{array}{ll}
\alpha H_{0}, & t=0 \\
U_{t-1}\left(1+\mathrm{ER}_{0}+\mathrm{RS} 2\right)-\bar{M}, & t=1, \ldots, T
\end{array} .\right.
$$

The mortgage payment would be reduced by a fraction of a percentage point per a percentage point reduction in the house price (relative to the house price at loan origination). The actual amount $M_{t}$ due at time $t$ is determined by the value of the associated property index at time

\footnotetext{
${ }^{4}$ The purpose of the penalty is to avoid strategic prepayments. A prepayment at the time of a deep adjustment would allow the borrower to lock in the low balance, thereby causing a substantial loss to the lender. It should be emphasized that a loan adjustment is not equivalent to a principal write down; for the former, the balance would revert to the reference balance when the real estate market rebounds; for the latter, the reduction in principal is permanent.
} 
$t-1 ;$ that is, for $t=0,1, \ldots, T-1$,

$$
M_{t+1}=\min \left\{\bar{M}, \bar{M}\left[1-\kappa\left(1-\frac{I_{t}}{I_{0}}\right)\right]\right\}=\min \left\{\bar{M}, \bar{M}\left[1-\kappa\left(1-\frac{H_{t}}{H_{0}}\right)\right]\right\}
$$

where $0 \leq \kappa \leq 1$ is the 'workout proportion', which indicates how many percentage points the mortgage payment would reduce per a percentage point decrease in the property index. ${ }^{5}$ The second equality in the equation above is due to our assumption that there is no basis risk. Note that we also have $M_{1}=\bar{M}$ for the PILM2.

The post-adjustment loan balance ${ }^{6}$ at time $t$ is defined to be the present value of all future payments, assuming they all equal $M_{t+1}$; that is,

$$
B_{t}=M_{t+1} \frac{1-\left(1+\mathrm{ER}_{0}+\mathrm{RS} 2\right)^{t-T}}{\mathrm{ER}_{0}+\mathrm{RS} 2}, \quad t=1, \ldots, T-1
$$

The specification of the prepayment penalty is the same as that for PILM1 contracts, except that PRE1 is replaced with another parameter PRE2 that lies between 0 and 1.

\subsection{Comparison of PILM1 and PILM2}

The two PILM designs have the same main objective: to reduce the homeowners' mortgage payments in a depressed housing market. However, the adjustment mechanisms are different when there is a drop in house prices. Under a PILM1 the first step is to reduce the outstanding balance and the payment is adjusted in the next step. Under a PLIM2 the initial step is to reduce the mortgage payment and the loan balance is revised in the subsequent step on the basis of the reduced payment. This section compares these two mortgage designs and uses a numerical example to illustrate the main differences.

By definition, the balance adjustment for PILM1 depends on both the current property value $H_{t}$ and the reference balance $U_{t}$. Towards the end of the mortgage term, $U_{t}$ becomes small so it is more difficult to trigger an adjustment and even if an adjustment is triggered it tends to be mild. In sharp contrast, for PILM2, an adjustment is triggered as long as the current property value $H_{t}$ is lower than the initial value $H_{0}$. Because the reference payment $\bar{M}$ is constant over time, the chance for triggering remains even throughout the loan term.

We use a simple numerical example to demonstrate the aforementioned differences. Assume that the property value is $H_{0}=400$ initially, falls to 300 before the first payment is due, and remains constant thereafter. Assume further that $T=30, \alpha=0.95, \bar{\alpha}=1, \kappa=0.5$ and the contract rate for all mortgages is 0.05 .

Figure 1 displays the loan balances and mortgage payments for all three contracts over time. Note that all contracts have the same first payment, because it takes one period for any PILM

\footnotetext{
${ }^{5}$ The adjustment scheme and the term 'workout proportion' are taken from Shiller et al. [34].

${ }^{6}$ Determining the loan balance for a PILM2 contract is operationally difficult, but we need a definite formula for $B_{t}$ in order to compute prepayment penalties. Shiller et al. [34] define the loan balance of a continuous workout mortgage as the expected present value of all future payments under a certain risk-neutral measure, whereas Mian and Sufi [31] define the loan balance for a shared-responsibility mortgage as the balance specified in the amortization schedule established at loan origination.
} 

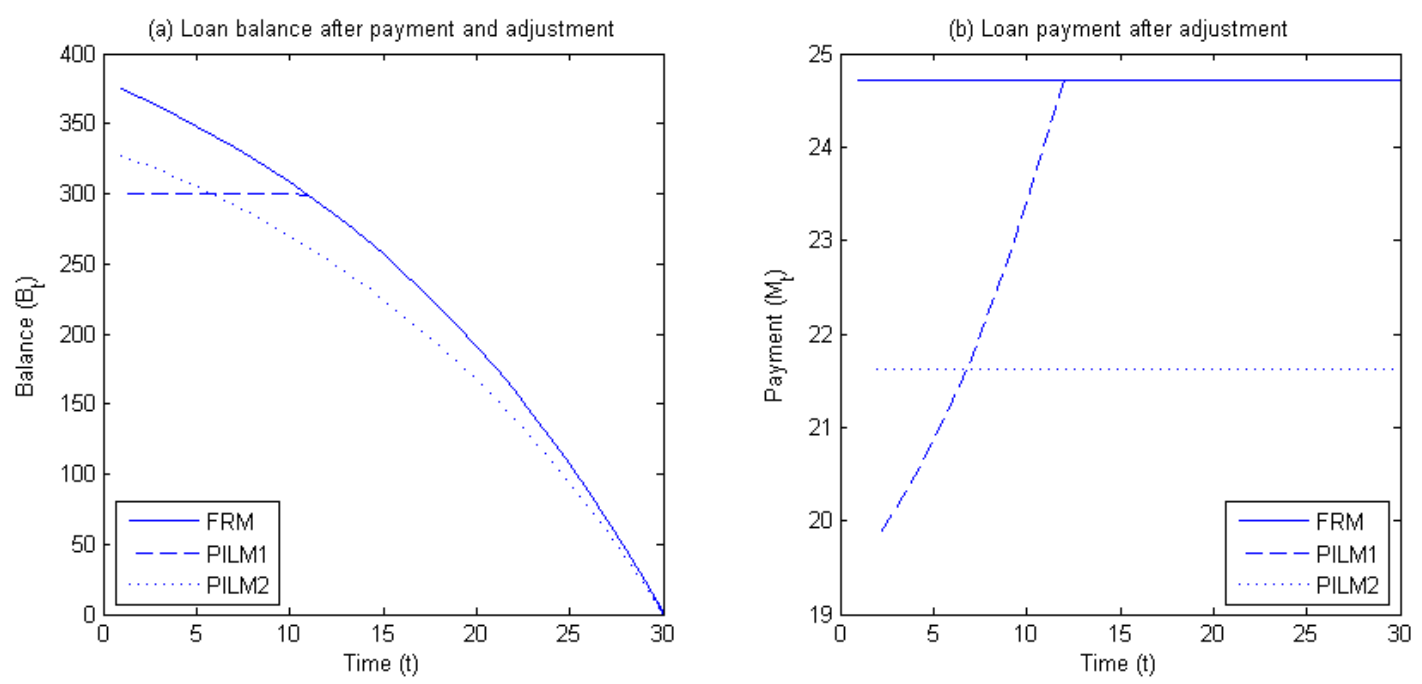

Figure 1: A comparison of the loan balances (the left panel) and mortgage payments (the right panel) among the three contracts under consideration. The values are based on the hypothetical situation that the property value is $H_{0}=400$ initially, falls to 300 before the first payment is due, and remains constant thereafter. It is assumed that the amortization term is 30 years, the contract rate for all three contracts is 0.05 , the initial LTV is $\alpha=0.95$, the target LTV is $\bar{\alpha}=1$ and the workout proportion is $\kappa=0.5$.

adjustment to realize and a loan adjustment at $t=0$ is impossible. For the FRM contract, the mortgage payment is constant over the entire mortgage term. For the PILM1 contract, there is a sharp reduction in payment at $t=2$, but the payment then increases gradually until it reaches its original level at $t=12$. The reason behind the increasing trend in payment is that at each time point from $t=1$ to $t=10$ the PILM1 balance is adjusted to 300 and the loan is re-amortized over the remaining term. As $t$ increases, the re-amortization period shortens, causing the payment to increase. The increase ends at $t=12$, because starting at $t=11$ the values of $U_{t}$ are lower than 300 and hence no adjustment is triggered. For the PILM2 contract, the payment does not change after $t=2$ because the adjustment depends solely on the property value, which is assumed to remain constant after dropping to $300 .{ }^{7}$ This example demonstrates that given a one-time drop in house price in early mortgage years, the payment adjustment under a PILM1 contract is intense initially but weakens as the loan ages, while the payment adjustment under a PILM2 contract (with $\kappa<1$ ) is less intense initially but tends to last longer. ${ }^{8}$

\footnotetext{
${ }^{7}$ Under a PILM1 contract, the payment reduction (as a proportion of the reference payment) at $t=2$ is the same as the loan balance reduction as a proportion of the reference balance at $t=1$ :

$$
\frac{\alpha H_{0}\left(1+\mathrm{ER}_{0}+\mathrm{RS} 1\right)-\bar{M}-f H_{0}}{\alpha H_{0}\left(1+\mathrm{ER}_{0}+\mathrm{RS} 1\right)-\bar{M}},
$$

which approximately equals to $\frac{\alpha-f}{\alpha}$ when $T$ is large, where $f$ is the current to initial house price ratio that is small enough to trigger an adjustment. In our hypothetical scenario, $f=0.75$ and the payment reduction at $t=2$ (calculated using the approximation) is $21 \%$. Under a PILM2 contract, the payment reduction at $t=2$ is exactly $\kappa(1-f)$, which equals $12.5 \%$ in our hypothetical scenario. If $\alpha=1$, the PILM2 payment reduction would be smaller than the PILM1 payment reduction by a fraction of $\kappa$.

${ }^{8}$ Given the same contract rate, a PILM2 with a full workout $(\kappa=1)$ dominates a PILM1 with a target LTV $\bar{\alpha}$ no smaller than the initial LTV $\alpha$. Consider the situation when the payment adjustments of both PILMs are
} 


\section{The Borrower's Problem and Its Solution}

In this section we define the borrower's problem and explain how to solve it. Our approach is similar to that of Campbell and Cocco [10, 11] but is modified to reflect the problem at hand. We assume the borrower has just taken out a generic mortgage and we model his/her choices using a discrete time framework. At each time point after loan origination, the borrower takes the optimal action that maximizes his/her expected utility of consumption. Consumption depends on the borrower's choice, the mortgage payment and the housing market. Our goal is to find the borrower's optimal choice under all possible conditions that he/she may face. These choices characterize the borrower's behaviour, and the associated maximized utility reflects the borrower's welfare. The behaviour and welfare are different under different mortgage contracts, and they are compared in Sections 4 and 5.

Mathematically, the borrower's problem at loan origination can be expressed as

$$
\max _{\left\{A_{1}, \ldots, A_{T}\right\}} U\left(C_{0}\right)+E_{0}\left[\sum_{t=1}^{T} \beta^{t} U\left(C_{t}\left(A_{t}\right)\right)+\beta^{T} V\left(H_{T}, A_{T}\right)\right],
$$

where $E_{t}[\cdot]$ denotes the expectation given all information up to and including time $t, C_{t}\left(A_{t}\right)$ represents the time- $t$ consumption given that action $A_{t}$ is taken at time $t, \beta$ is the subjective rate of time preference,

$$
U(x)=\frac{x^{1-\gamma}}{1-\gamma}
$$

is the utility function with constant relative risk aversion $\gamma \neq 1$, and $V(\cdot, \cdot)$ is the bequest function. The objective function is maximized over all feasible actions $\left\{A_{1}, \ldots, A_{T}\right\}$. In what follows, we specify the feasible set of actions, the relationship between actions and consumption and the bequest function.

At each time point the borrower is endowed with a constant non-storable income $L$ and takes action $A_{t}$. In particular, the borrower can choose one of the following three actions before the mortgage loan is terminated:

- Continue to repay $\left(A_{t}=P\right)$

The borrower may choose to pay the amount due $M_{t}$ and receive the ownership benefit $s H_{t}$, where $s$ denotes the constant benefit rate. ${ }^{9}$ The consumption from the ownership benefit is in addition to the consumption from the income.

- Refinance $\left(A_{t}=R\right)$

triggered. On the basis of the adjustment formulas, the balance of the PILM1 would be adjusted to $\bar{\alpha} H_{t}$, while the balance of the PILM2 with $\kappa=1$ would be adjusted to $U_{t} \frac{H_{t}}{H_{0}}$. Since $U_{t} \leq \alpha H_{0} \leq \bar{\alpha} H_{0}$, the balance of the PILM2 never exceeds that of the PILM1. For a meaningful comparison between the two contract types, we do not consider PILM2s with a full workout.

${ }^{9}$ The ownership benefit can be interpreted as the extra utility arising from owning the property, in addition to the benefit of living in the property. This benefit could be pecuniary and/or psychological and increases with the value of the mortgaged property. 
The borrower may choose to refinance the existing loan into another loan with an initial balance that equals the post-adjustment balance $B_{t}$ of the original loan plus the prepayment penalty $\mathrm{PP}_{t}$ and a contract rate that equals the current market mortgage rate $\mathrm{MR}_{t}$. We permit the borrower to refinance at any time and as many times as he/she wishes. ${ }^{10}$ For simplicity, we assume that the new loan is always a FRM and that there is only one prevailing market rate which applies to all FRM loans, regardless of the loan term. If this action is chosen, the borrower would pay the amount due $M_{t}$, pay the refinancing cost $\mathrm{RC}$ and receives the ownership benefit $s H_{t}$.

- Default $\left(A_{t}=D\right)$

The borrower may choose to default, so that the mortgage contract is terminated and the property is foreclosed. If this action is chosen, the borrower would not pay the amount due, but incur a default cost DC and receive no ownership benefit. ${ }^{11}$ For the remaining of his/her life, the borrower would have to seek housing in the rental market. The rental property is assumed to provide the same living utility as the foreclosed property, but give no ownership benefit.

If the borrower defaults, then he/she has to rent a property and pay the rent $Y_{t}$. The action of renting a property is denoted by $A_{t}=N$. Given the aforementioned assumptions, we see that after defaulting, the borrower would no longer need to make decisions as $N$ is the only possible action. Moreover, in a feasible sequence of actions $\left\{A_{t}, t=1,2, \ldots, T\right\}$ there can be at most one $D$, and if $A_{t}=D$ then $A_{t+1}=A_{t+2}=\ldots=A_{T}=N$.

Since income is assumed to be non-storable and the assumed utility function is strictly increasing, it is optimal for the borrower to consume all income left after his/her housing expenditure. It follows that for $t=1,2, \cdots, T$,

$$
C_{t}\left(A_{t}\right)=\left\{\begin{array}{lcc}
L-M_{t}+s H_{t} & \text { if } & A_{t}=P \\
L-M_{t}+s H_{t}-\mathrm{RC} & \text { if } & A_{t}=R \\
L-\mathrm{DC} & \text { if } & A_{t}=D \\
L-Y_{t} & \text { if } & A_{t}=N
\end{array} .\right.
$$

The rent $Y_{t}$ is assumed to be an increasing function of property value at the previous time point:

$$
Y_{t}=\min \left(\bar{Y}, c H_{t-1}\right)
$$

where $0<c<1$ is a constant and $0<\bar{Y}<L$ is the cap of the rent. ${ }^{12}$ The cap is imposed to

\footnotetext{
${ }^{10}$ This means that there is no requirement on the property value at the time of refinancing.

${ }^{11}$ In our set-up, both DC and RC are not retained by the lender. We assume that the lender has no recourse on the borrower's income.

${ }^{12}$ We acknowledge that the actual relationship between house prices and rents is more complicated. The historical values of the S\&P/Case-Shiller 10-City Composite Home Price Index and the Owners' Equivalent Rent of Primary Residence Index indicate that rents increased with house prices from 1992 to 2005 , but after the burst of the real estate bubble in 2006 home prices fell by about $1 / 3$ while rents kept rising. The values of the home price and rent indexes can be retrieved at http://ca.spindices.com/indices/real-estate/ sp-case-shiller-10-city-composite-home-price-index and http://research.stlouisfed.org/fred2/
} 
ensure that default is always 'affordable'. The time-0 consumption is given by

$$
C_{0}=L-(1-\alpha) H_{0}-\mathrm{IP} \cdot \alpha H_{0}
$$

where IP denotes the upfront costs to the borrower as a percentage of the loan size.

We let $\mathrm{ER}_{t}$ be the effective rate at which the current FRM mortgage payment $M_{t}$ is calculated. The value of $\mathrm{ER}_{t}$ depends on the borrower's action. If the borrower chooses to refinance at time $t$, then the subsequent mortgage payments would be (re-)calculated on the basis of the prevailing market mortgage rate $\mathrm{MR}_{t}$. If the borrower chooses to continue repaying the current loan, then $\mathrm{ER}_{t}$ would simply be the same as $\mathrm{ER}_{t-1}$. If the borrower chooses to default or has already defaulted, then $\mathrm{ER}_{t}$ becomes irrelevant to the borrower's problem and we set it to 0 for convenience. Hence, we have

$$
\mathrm{ER}_{t+1}\left(A_{t}\right)=\left\{\begin{array}{lll}
\mathrm{ER}_{t} & \text { if } & A_{t}=P \\
\mathrm{MR}_{t} & \text { if } & A_{t}=R \\
0 & \text { if } & A_{t}=D, N
\end{array}\right.
$$

for $t=1,2, \cdots, T-1$ and $\mathrm{ER}_{1}=\mathrm{ER}_{0}$.

Depending on the contract type, the mortgage payment responds to the borrower's action differently. For FRMs,

$$
M_{t+1}\left(A_{t}\right)=\left\{\begin{array}{ll}
M_{t} & \text { if } \quad A_{t}=P \\
M_{t} \frac{1-\left(1+\mathrm{ER}_{t}\right)^{t-T}}{\mathrm{ER}_{t}} \frac{\mathrm{MR}_{t}}{1-\left(1+\mathrm{MR}_{t}\right)^{t-T}} & \text { if } \quad A_{t}=R \\
0 & \text { if } \quad A_{t}=D, N
\end{array} ;\right.
$$

for PILM1s,

$$
M_{t+1}\left(A_{t}\right)= \begin{cases}B_{t} \frac{\mathrm{ER}_{0}+\mathrm{RS} 1}{1-\left(1+\mathrm{ER}_{0}+\mathrm{RS} 1\right)^{t-T}} & \text { if } \quad A_{t}=P \\ \left(B_{t}+\mathrm{PP}_{t}\right) \frac{\mathrm{MR}_{t}}{1-\left(1+\mathrm{MR}_{t}\right)^{t-T}} & \text { if } \quad A_{t}=R \\ 0 & \text { if } \quad A_{t}=D, N\end{cases}
$$

and for PILM2s,

$$
M_{t+1}\left(A_{t}\right)= \begin{cases}\min \left\{\bar{M}, \bar{M}\left[1-\kappa\left(1-\frac{H_{t}}{H_{0}}\right)\right]\right\} & \text { if } \quad A_{t}=P \\ \left(B_{t}+\mathrm{PP}_{t}\right) \frac{\mathrm{MR}_{t}}{1-\left(1+\mathrm{MR}_{t}\right)^{t-T}} & \text { if } \quad A_{t}=R \\ 0 & \text { if } \quad A_{t}=D, N\end{cases}
$$

where $t=1,2, \cdots, T-1$. Note that $M_{1}=\alpha H_{0} \frac{\mathrm{ER}_{0}}{1-\left(1+\mathrm{ER}_{0}\right)^{-T}}$ for FRMs and $M_{1}=\bar{M}$ for PILMs.

The housing market is characterized by two variables: the property value $H_{t}$ and the market 
mortgage rate $\mathrm{MR}_{t}$. We assume that these variables follows the Markovian processes below:

$$
\left\{\begin{array}{l}
\log H_{t+1}=\log H_{t}+\left(\mu_{H}-\frac{1}{2} \sigma_{H}^{2}\right)+\sigma_{H} Z_{H} \\
\log \mathrm{MR}_{t+1}=\log \mathrm{MR}_{t}+\left(\mu_{\mathrm{MR}}-\frac{1}{2} \sigma_{\mathrm{MR}}^{2}\right)+\sigma_{\mathrm{MR}} Z_{\mathrm{MR}}
\end{array},\right.
$$

where $\mu_{H}$ and $\mu_{\mathrm{MR}}$ are the rates of appreciation, $\sigma_{H}$ and $\sigma_{\mathrm{MR}}$ are the volatilities, and $\left(Z_{H}, Z_{\mathrm{MR}}\right)$ follows a standard bivariate normal distribution with a correlation coefficient $\rho$. Non-Markovian processes may more realistically capture the dynamics of house prices and market mortgage rates, but will substantially increase the number of state variables and hence computational burden. ${ }^{13}$ In principle, there could be two sets of parameters. One could reflect the market perceived by the borrower, while the other the real market. If the two sets of parameters coincide, then the borrower behaves optimally; otherwise he/she does not.

Finally, we specify the bequest function $V\left(H_{T}, A_{T}\right)$, which represents the total utility, discounted to $t=T$, of the consumption after (but not including) $T$. Assuming that the property value remains constant after time $T$ and that the borrower has a non-random lifespan of $T_{L}$ measured from loan origination, we have

$$
V\left(H_{T}, A_{T}\right)=\left\{\begin{array}{llc}
\sum_{t=1}^{T_{L}-T} \beta^{t} U\left(L+s H_{T}\right) & \text { if } & A_{T}=P, R \\
\sum_{t=1}^{T_{L}-T} \beta^{t} U\left(L-Y_{T+1}\right) & \text { if } & A_{T}=D, N
\end{array} .\right.
$$

In this expression, condition ' $A_{T}=D, N$ ' implies that $A_{t}=D$ for some $1 \leq t \leq T$ and thus the borrower no longer owns the property at time $T$; condition ' $A_{T}=P, R$ ' implies that default has never occurred over the term of the mortgage and therefore the borrower owns the property at time $T$.

It is clear that owning the property always derives a higher bequest and that how much homeownership affects bequest depends on the end-of-term property value. From the expressions for $V\left(H_{T}, A_{T}\right)$ and $C_{t}\left(A_{t}\right)$ we can infer that each mortgage decision depends critically on bequest, ownership benefit and rent. According to our set-up, when the property value declines, the expected bequest decreases, the current ownership benefit drops and renting a property becomes more attractive. The linkage of mortgage decisions to these three quantities allows us to capture the potential relationship between the property value and the propensity to default.

The actions chosen depend on the environment that is fully characterized by the following state variables, $t, H_{t}, \mathrm{MR}_{t}, \mathrm{ER}_{t}, M_{t}$ for FRMs and $t, H_{t}, \mathrm{MR}_{t}, M_{t}$ for PILMs. Note that $t, H_{t}, \mathrm{MR}_{t}$ do not depend on the borrower's decisions, but $\mathrm{ER}_{t}$ and $M_{t}$ do. We do not need to include $\mathrm{ER}_{t}$ as a state variable when modeling a PILM. This is because if the borrower

\footnotetext{
${ }^{13}$ Campbell and Cocco [11] also use a geometric Brownian motion for modeling property values but a first order autoregression for modeling interest rates. More sophisticated approaches to modeling house prices and market mortgage rates are considered by Kau et al. [26], Hanewald and Sherris [23], Li et al. [28] and the FHA actuarial review [25].
} 
continues to repay at time $t$ then $\mathrm{ER}_{t}$ is identical to $\mathrm{ER}_{0}$, and if not then the PILM contract is terminated. However, we still need to include $M_{t}$ when modeling a PILM because it is related to $H_{t-1}$.

We solve the borrower's problem by dynamic programming (similar to the method used in Campbell and Cocco $[10,11])$. Define the time- $t$ value of a mortgage contract as the optimized expected discounted utilities of future consumption starting at time $t$; that is,

$$
\max _{\left\{A_{t}, A_{t+1}, \cdots, A_{T}\right\}} U\left(C_{t}\right)+E_{t}\left[\sum_{i=t+1}^{T} \beta^{i-t} U\left(C_{i}\left(A_{i}\right)\right)+\beta^{T-t} V\left(H_{T}, A_{T}\right)\right] .
$$

We use $J_{t}^{k}$, where $k \in\{$ FRM, PILM1, PILM2 $\}$ and $t=1, \ldots, T$, to represent the time- $t$ value of mortgage contract $k$. The value of $J_{t}^{k}$ depends on all state variables that are applicable to the specific contract type. We further define the value of an action as the optimal utility derived from taking the action; that is,

$$
I_{t}^{k}\left(A_{t}\right)=\left\{\begin{array}{lll}
U\left(C_{t}\left(A_{t}\right)\right)+\beta E_{t}\left[J_{t+1}^{k}\right] & \text { if } \quad A_{t}=P, D, N \\
U\left(C_{t}\left(A_{t}\right)\right)+\beta E_{t}\left[J_{t+1}^{\mathrm{FRM}}\right] & \text { if } \quad A_{t}=R
\end{array},\right.
$$

for $t=1,2, \cdots, T-1$, and

$$
I_{T}^{k}\left(A_{T}\right)=U\left(C_{T}\left(A_{T}\right)\right)+V\left(H_{T}, A_{T}\right) .
$$

The expectations in the above expression are taken with respect to $\left(H_{t+1}, \mathrm{MR}_{t+1}\right)$. It follows that the contract value is the maximum over all feasible actions:

$$
J_{t}^{k}=\left\{\begin{array}{lll}
\max \left\{I_{t}^{k}(P), I_{t}^{k}(R), I_{t}^{k}(D)\right\} & \text { if } & M_{t}>0 \\
I_{t}^{k}(N) & \text { if } & M_{t}=0
\end{array},\right.
$$

for $t=1,2, \cdots, T$. Note that in the above expression, condition ' $M_{t}=0$ ' is equivalent to the condition that default occurs prior to time $t$.

Since refinancing at time $T$ is never optimal, ${ }^{14}$ the terminal contract value can be simplified to

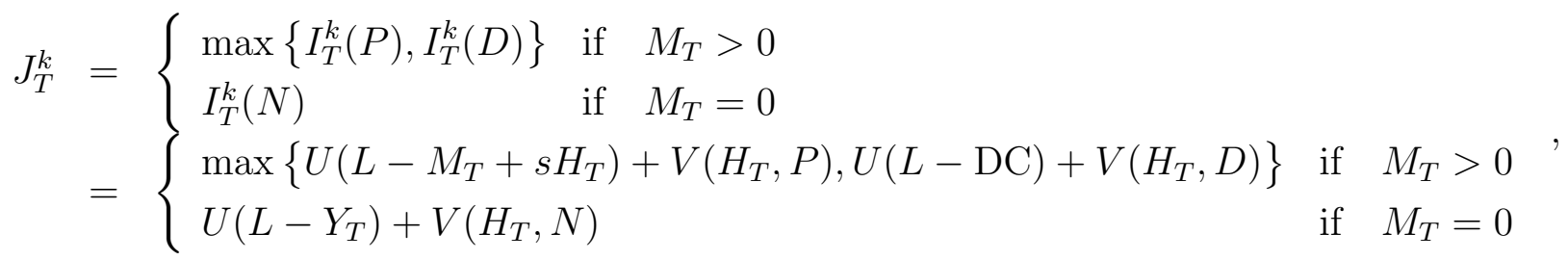

which can be computed for all possible states. Therefore, we can compute the values of $J_{t}^{k}$ for $t=1, \ldots, T-1$ and the associated optimal actions by a backward recursion which starts at $t=T$. As we reach the end of the backward recursion, we obtain the contract value at loan

\footnotetext{
${ }^{14}$ After making a payment of $M_{T}$, the loan balance becomes zero. Refinancing at time $T$ therefore brings no benefit but incurs a cost of RC.
} 
origination:

$$
J_{0}^{k}=U\left(C_{0}\right)+\beta E_{0}\left[J_{1}^{k}\right] .
$$

Recall the assumption that a PILM can only be refinanced into a FRM. Because the value of a PILM refinancing depends on the corresponding FRM's contract value, we need to perform the recursion for a FRM first before that for the corresponding PILMs.

\section{Analysis of Borrower Behaviour}

This section implements the model we developed in the last section and discusses the results. We start with a description of the parameter values used in our baseline calculation and discuss the rationale for the values selected. Then we analyze the borrower's optimal behaviour under different economic conditions. In particular we examine how the incentives to default, maintain the current mortgage and refinance depend on mortgage rates and property values across the three contracts. We are especially interested in the differences between the two PILM designs. Our analysis includes the borrower's behaviour at a fixed time point as well as over time. Finally we compare both the borrower's and the lender's welfare under the three contracts by simulation.

\subsection{The Baseline Parameter Values}

The baseline parameter values used in the analysis are displayed in Table 1 . We now discuss these choices and explain our justification.

\section{Parameters related to the mortgage contracts}

We consider 30-year mortgages with an initial LTV of $\alpha=0.95$ for a property valued $H_{0}=400$ at time 0 . Each time period corresponds to 1 year. The assumed upfront cost (as a percentage of the loan amount) is IP $=2 \%$, which includes the initial points charged by the lender (approximately $0.7 \%$ over the period of 2009 to $2013^{15}$ ), commissions, legal fees and appraisal fees. The initial FRM contract rate $\mathrm{ER}_{0}$ is set to the market mortgage rate $\mathrm{MR}_{0}$ at time 0 . In the baseline calculations, we assume that PILM lenders do not demand a rate spread (i.e., $\mathrm{RS} 1=\mathrm{RS} 2=0$ ). The chosen values of $\bar{\alpha}, \kappa$, and PRE1, PRE2 are arbitrary, but will be sensitivity tested in Section 5.

Parameters related to the housing market (resale and rental)

We set $\mathrm{MR}_{0}$ to $5 \%$, because the average Federal Housing Administration (FHA) 30year FRM mortgage rate was $5.23 \%$ in 2010 and has been reducing since then. ${ }^{16}$ We assume a refinancing cost of 6 , which is lower than the upfront cost of the original loan $(400 \times 0.95 \times 0.02=7.6)$, on the grounds that the loan balance at the time of refinancing

\footnotetext{
${ }^{15}$ Source: Freddie Mac Primary Mortgage Market Survey for Conventional Conforming 30-year FRM.

${ }^{16}$ Source: FHA Mortgage Insurance Single-Family 30-Year Fixed Interest Rates, available at http://portal . hud.gov/hudportal/HUD?src=/program_offices/housing/rmra/oe/rpts/rates/irmenu.
} 


\begin{tabular}{|c|c|c|}
\hline Parameter & Description & Value \\
\hline \multicolumn{3}{|l|}{ Contract } \\
\hline$T$ & Mortgage term (years) & 30 \\
\hline$\alpha$ & Initial LTV & 0.95 \\
\hline IP & Upfront cost (as a fraction of the loan amount) & 0.02 \\
\hline $\mathrm{ER}_{0}$ & Initial FRM contract rate & 0.05 \\
\hline $\bar{\alpha}$ & Target LTV for PILM1 & 1 \\
\hline RS1 & Rate spread for PILM1 & 0 \\
\hline PRE1 & Prepayment penalty parameter for PILM1 & 1 \\
\hline$\kappa$ & Workout proportion for PILM2 & 0.5 \\
\hline RS2 & Rate spread for PILM2 & 0 \\
\hline PRE2 & Prepayment penalty parameter for PILM2 & 1 \\
\hline \multicolumn{3}{|c|}{ Housing market (resale and rental) } \\
\hline$H_{0}$ & Initial property value & 400 \\
\hline $\mathrm{MR}_{0}$ & Initial market mortgage rate & 0.05 \\
\hline$\mu_{H}$ & Rate of appreciation of property values & 0 \\
\hline$\sigma_{H}$ & Volatility of property values & 0.1 \\
\hline$\mu_{\mathrm{MR}}$ & Rate of appreciation of mortgage rates & 0 \\
\hline$\sigma_{\mathrm{MR}}$ & Volatility of mortgage rates & 0.1 \\
\hline$\rho$ & Correlation between the log-returns on $H_{t}$ and $\mathrm{MR}_{t}$ & 0 \\
\hline $\mathrm{DC}$ & Default cost & 10 \\
\hline $\mathrm{RC}$ & Refinancing cost & 6 \\
\hline$s$ & Ownership benefit (as a fraction of the property value) & 0.02 \\
\hline $\bar{Y}$ & Upper bound of rents & 25 \\
\hline$c$ & Rent-to-price ratio & 0.05 \\
\hline \multicolumn{3}{|c|}{ Borrower's characteristics } \\
\hline$L$ & Annual income & 70 \\
\hline$\beta$ & Intertemporal utility discount & 0.96 \\
\hline$\gamma$ & Coefficient of relative risk aversion & 3 \\
\hline$T_{L}$ & Lifespan measured from loan origination (years) & 60 \\
\hline
\end{tabular}

Table 1: The baseline parameter values used in analyzing borrowers' behaviour.

is lower than that at time 0 . We assume a default cost of 10 and an ownership benefit of $2 \%$ of the property value. These two values vary among borrowers, depending on various nonpecuniary factors including credit degradation, social stigma and the desire for homeownership.

In the baseline calculations, we assume that the borrower's subjective view on the housing market coincides with the actual market (i.e., only one set of $\mu_{H}, \sigma_{H}, \mu_{\mathrm{MR}}, \sigma_{\mathrm{MR}}$ and $\rho$ is used). We also assume that property values and market mortgage rates are volatile $\left(\sigma_{H}=\sigma_{\mathrm{MR}}=0.1\right)$ but possess no trend $\left(\mu_{H}=\mu_{\mathrm{MR}}=0\right)$. What we are interested is a period of turmoil where default rates of the traditional FRM contract rise. The experience of the housing and mortgage markets in the past decade provides us with a good example. Based on the S\&P/Case-Shiller 10-city composite home price index from March 2004 to February 2014, the estimated house price appreciation rate is almost 0 and the estimated volatility is 0.11 . These estimates are close to our choices of baseline values. In Section 
5 we will examine how the results change if the parameters in the processes for $H_{t}$ and $\mathrm{MR}_{t}$ are calibrated to longer history.

Over the period of October 1992 to February 2014, the sample correlation between the annual log-returns on the S\&P/Case-Shiller 10-city composite home price index and the annual log-returns on the average FHA 30-year FRM rate is negative, but the sample correlation becomes positive if the conventional conforming 30-year FRM rate is considered instead. Because the sample correlation takes no definite sign, we set $\rho$ to zero in our baseline calculations.

The time- $t$ rent is a fraction $c=0.05$ of the house price at time $t-1$, subject to a maximum of $\bar{Y}=25$. Campbell and Cocco [11] permit the fraction to vary with the prevailing interest rate, but for simplicity we assume that it is the same as the initial mortgage rate $\mathrm{MR}_{0}$ and remains constant throughout the term of the mortgage.

\section{$\underline{\text { Parameters related to the borrower's characteristics }}$}

Given the assumed values of $\alpha, H_{0}$ and $\mathrm{MR}_{0}$, the annual mortgage payment for a 30year FRM is 24.72. The assumed borrower's income $L=70$ implies that the ratio of mortgage payment to income is $35.31 \%$. This ratio is in between FHA's limit on the housing-related expense to income ratio, which is about $31 \%$, and FHA's limit on the total recurrent expense to income ratio, which is about $43 \% .{ }^{17}$ We assume that the borrower will live $T_{L}=60$ years after the inception of the mortgage. ${ }^{18}$ Following Cocco et al. [13], we set the utility discount $\beta$ to 0.96. Following Campbell and Cocco [10] and Kung [27], we assume that the coefficient of relative risk aversion $\gamma$ is 3 .

\subsection{Optimal Borrower Choices at Time One}

We now examine how the borrower's choice depends on different housing market environments at $t=1$. To do so we assume a borrower takes out a mortgage loan at $t=0$ and examine the borrower's optimal decision one year after loan origination under a range of house prices and market mortgage rates. This enables us to better understand how the borrower's decision is impacted by the prevailing market conditions. We carry out the analysis for our three mortgage contracts. For the FRM contract the results are consistent with the historical experience. If interest rates fall it is optimal to refinance the loan at a lower rate, if house prices have dropped it is optimal to default, and if neither happens it is optimal to continue with the current loan. For the PILM contracts we find the same broad patterns but the results are more nuanced. For example, we find that under some conditions a PILM borrower will optimally continue where a FRM borrower would either default or refinance.

In Figure 2 we show, for each contract, the optimal actions at $t=1$ under different combinations of log property value and log mortgage rate. We use 'o' to indicate that continuing to

\footnotetext{
${ }^{17}$ Source: http://portalapps.hud.gov/FHAFAQ/controllerServlet?method=showPopup\&faqId=1-6KT-1040.

${ }^{18}$ According to the Human Mortality Database (www.mortality.org), the life expectancy of a 22-year-old U.S. female in 2010 is approximately 60 years.
} 
repay is the optimal action, ' + ' to indicate refinancing is optimal and ' $\mathrm{x}$ ' to indicate default is optimal. The black dot represents the time-0 log property value (5.99) and log mortgage rate $(-3.00)$, so it is easy to read from the figure that how a deviation of time one market condition from time zero condition impacts the borrower's decision.

The optimal actions for the three contracts are roughly the same when the property value and mortgage rate are extremely high and/or low: (1) when both the property value and mortgage rate are very high, continuing to repay is optimal because both the refinancing and default options are deep out-of-the-money; (2) when the mortgage rate is very low but the property value is very high, refinancing is optimal as it reduces loan payment and a PILM adjustment is not likely to be triggered; (3) when the property value is very low, default becomes optimal. However, the three contracts are quite different in terms of the default boundary, which refers to the highest property value at which the borrower finds it optimal to default. It is clear that the PILMs have lower default boundaries, because they provide payment reductions at times when the property value is low. To obtain a better understanding of the differences between the three contracts, in what follows we study Figure 2 in greater depth.

We first compare the FRM with the two PILMs. For the FRM, default and refinancing compete with each other in the low-property-value-low-mortgage-rate region. The competition arises because the borrower's propensity to default increases when the value of his/her home equity drops but the amount of mortgage payment also decreases when the loan is refinanced at a lower rate. In this region, the borrower defaults if the effect of a low property value is stronger than that of a low mortgage rate, and refinances otherwise. For the PILMs, continuing to repay also plays a role in the competition due to the possibility of a loan adjustment. When the property value declines, default is less attractive to a PILM borrower than to a FRM borrower, because PILMs offer a partial compensation through a reduction in mortgage payments. For this reason, the PILMs have lower default boundaries in comparison to the FRM. Due to the assumption that a PILM can only be refinanced into a FRM, the PILM borrowers lose the opportunity for loan adjustments as soon as they refinance. Because the benefit from the current and/or future loan adjustment(s) may outweigh that from refinancing, refinancing also becomes less attractive even when the market interest rate is low. Overall, the continuation region is larger in the diagrams for the PILMs than in the diagram for the FRM.

Next, we compare the two PILMs. We can account for the differences between the two PILMs by considering the following factors which determine their values:

1. the current loan adjustment (realized at $t=2$ );

2. the opportunity to receive future loan adjustments;

3. the option to refinance;

4. the option to default.

From Figure 2 we observe that the most striking distinction between the two PILMs is that it is more likely for the PILM1 borrower to continue when both property value and mortgage 


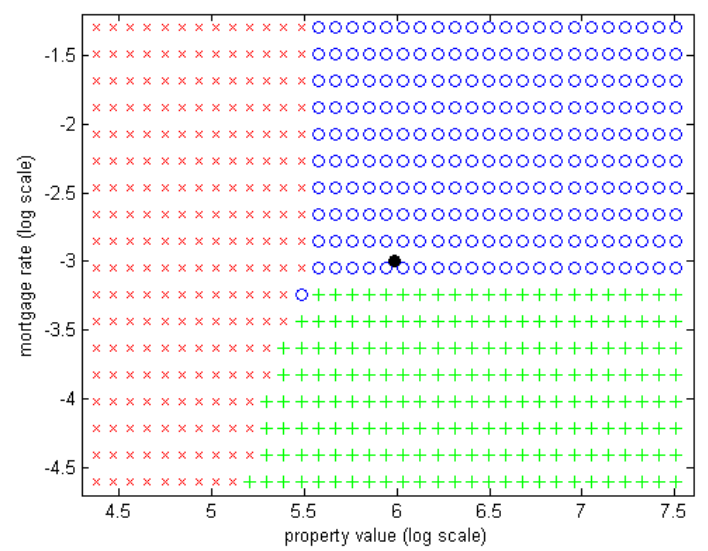

(a) FRM

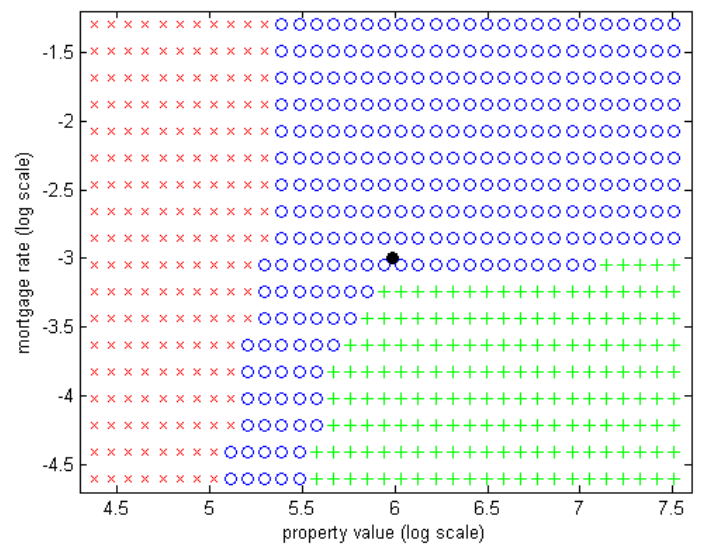

(b) PILM1

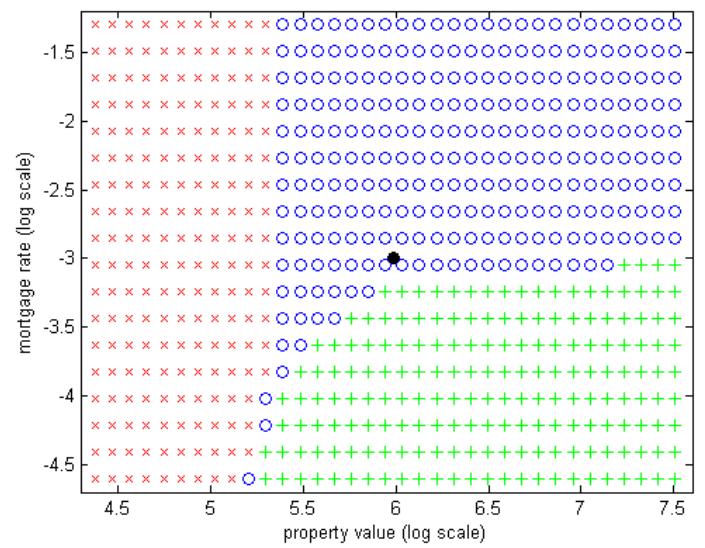

(c) PILM2

Figure 2: The optimal actions at $t=1$ under different combinations of $\log \left(H_{1}\right)$ and $\log \left(\mathrm{MR}_{1}\right)$. We use 'o', '+' and ' $x$ ' to represent continuing, refinancing and default, respectively. We use a black dot to indicate the time-0 log property value (5.99) and log mortgage rate $(-3.00)$.

rate are low. This outcome is a consequence of the two contracts' adjustment schemes, which we have illustrated in Section 2.4. When the property value plummets in early mortgage years, the loan adjustment provided by a PILM1 tends to be stronger at the outset but fades away over time. In a low interest rate environment, a PILM1 borrower can maximize benefit by continuing to repay for some time and then refinancing to lock in a low mortgage rate when the loan adjustment is no longer significant. In this way, the PILM1 borrower can enjoy the benefits from both the current loan adjustment and the option to refinance. By contrast, in the identical situation, the loan adjustment provided by a (partial workout) PILM2 tends to be milder but lasts longer. If a PILM2 borrower chooses to refinance, then a substantial amount of future loan adjustments would be lost; but if he/she chooses to repay, then the benefit of locking in a low mortgage rate would be forfeited. Thus, the PILM2 borrower can only benefit from loan adjustments or a low mortgage rate lock-in, but not both. It follows that in the first several years after mortgage origination, for some combinations of property value and mortgage rate under which the PILM1 borrower chooses to continue, the PILM2 borrower chooses not to. 


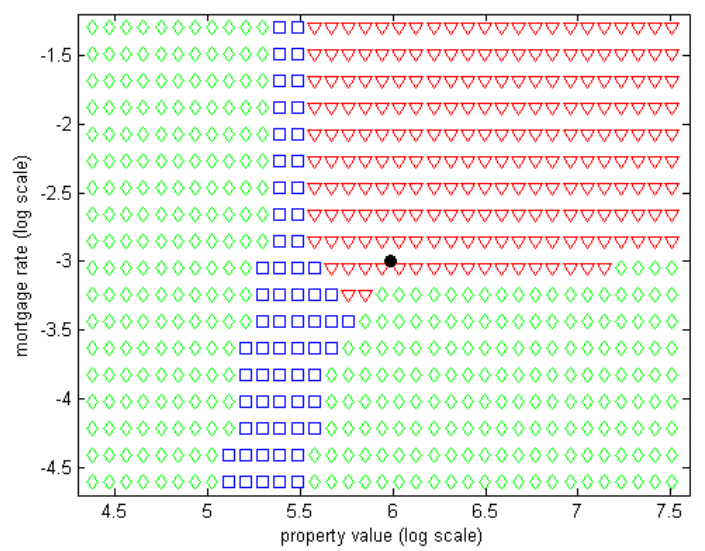

Figure 3: A comparison of the contract values of the two PILMs at $t=1$. We use ' $\square$ ' for the situation when the PILM1 has a higher value, ' $\nabla$ ' for the situation when the PILM1 has a lower value, and ' $\nabla$ ' for the situation when the two PILMs have the same value. We use a black dot to indicate the time-0 log property value (5.99) and log mortgage rate $(-3.00)$.

In Figure 3 we compare the contract values of the two PILMs under different combinations of property value and mortgage rate. We use ' $\square$ ' to indicate that PILM1 has a higher contract value, ' $\nabla$ ' to indicate that PILM2 has a higher value and ' $\nabla$ ' to indicate that the two PILMs have the same value. The black dot represents the time-0 log property value (5.99) and log mortgage rate $(-3.00)$. Note that upon default or refinancing, the two PILM borrowers have the same future consumption as they pay the same rents or make the same mortgage payments. ${ }^{19}$ It immediately follows that

$$
I_{t}^{\mathrm{PILM} 1}(D)=I_{t}^{\mathrm{PILM} 2}(D) \quad \text { and } \quad I_{t}^{\mathrm{PILM} 1}(R)=I_{t}^{\mathrm{PILM} 2}(R)
$$

for $t=1,2, \cdots, T$. Hence, the difference between the contract values of the two PILMs must arise when the two PILM borrowers have different optimal choices or when both PILM borrowers continue to repay. With this fact in mind, the pattern of the diagram in Figure 3 can be explained readily as follows:

$\underline{\text { Low mortgage rates and high property values; both borrowers refinance }}$

When the market mortgage rate is very low, refinancing becomes the optimal action

for both borrowers, which means the contract value is simply the value of refinancing.

Because $I_{1}^{\mathrm{PILM} 1}(R)=I_{1}^{\mathrm{PILM} 2}(R)$, both PILMs have the same contract value.

High mortgage rates and high property values; both borrowers continue

When the mortgage rate and property value are both high, both borrowers continue to repay even though there is currently no loan adjustment. At a high current property value, the chance of a future PILM2 adjustment is higher than that of a future PILM1 adjustment. This is because a PILM2 adjustment will be triggered once the property value

\footnotetext{
${ }^{19}$ We assume that if a PILM is refinanced, it must be refinanced into a FRM. Also, because we assume that PRE1 $=$ PRE2 and RS1 $=$ RS2 $=0$, the balance upon refinancing must be $U_{t}$, whose value is the same for both PILMs.
} 
becomes lower than the initial property value $H_{0}$, which is a fixed constant, whereas a PILM1 adjustment will be triggered only if the property value is lower than the reference balance $U_{t}$, which gradually diminishes to 0 over time. Therefore, the value of the opportunity to receive future loan adjustments for the PILM2 is higher, leading to $I_{1}^{\text {PILM1 }}(P)<I_{1}^{\text {PILM2 }}(P)$ and hence $J_{1}^{\text {PILM1 }}<J_{1}^{\text {PILM2 }}$.

Low property values; both borrowers default

When the property value is very low, default becomes the optimal action for both borrowers, which means the contract value is simply the value of default. Because $I_{1}^{\text {PILM1 }}(D)=$ $I_{1}^{\text {PILM2 }}(D)$, both PILMs have the same contract value.

Low property values; the borrowers behave differently

Note that the default boundary for the PILM1 is lower than or the same as that for the PILM2. When the time-1 property value is in between the default boundaries of the two PILMs, the PILM1 borrower continues to repay but the PILM2 borrower defaults. In such a situation, PILM1 has a higher contract value, because

$$
J_{1}^{\mathrm{PILM} 1}=I_{1}^{\mathrm{PILM} 1}(P)>I_{1}^{\mathrm{PILM} 1}(D)=I_{1}^{\mathrm{PILM} 2}(D)=J_{1}^{\mathrm{PILM} 2}
$$

Using a similar argument, we can explain why the PILM1 has a higher contract value in situations when the PILM1 borrower chooses to continue while the PILM2 borrower chooses to refinance.

Low property values; both borrowers continue

When the property value is low but still higher than the default boundaries of the PILMs, both borrowers continue to repay provided that the market interest rate does not justify refinancing. In this situation, as the property value approaches the default boundaries, the PILM1 has a higher contract value. This phenomenon may be explained by the fact that if the drop in the property price is very significant and occurs during early mortgage years, then the loan adjustment provided by a PILM1 is more pronounced than that provided by a PILM2.

\subsection{Optimal Borrower Choices Over Time}

In this sub-section we study how the borrower's behaviour vary with time. The borrower's propensity to default and refinance can be examined through default and refinancing boundaries. A low default boundary means the borrower defaults only when property value is low, implying a low propensity to default. Similarly a low refinancing boundary indicates a low propensity to refinance as the borrower only refinances when the market mortgage rate is low. These boundaries change over time and are different under different mortgage contracts.

Let us first focus on the trends in the default boundaries. In Figure 4 we show the default boundaries, calculated at a fixed market mortgage rate of $5 \%$, over the entire mortgage term 


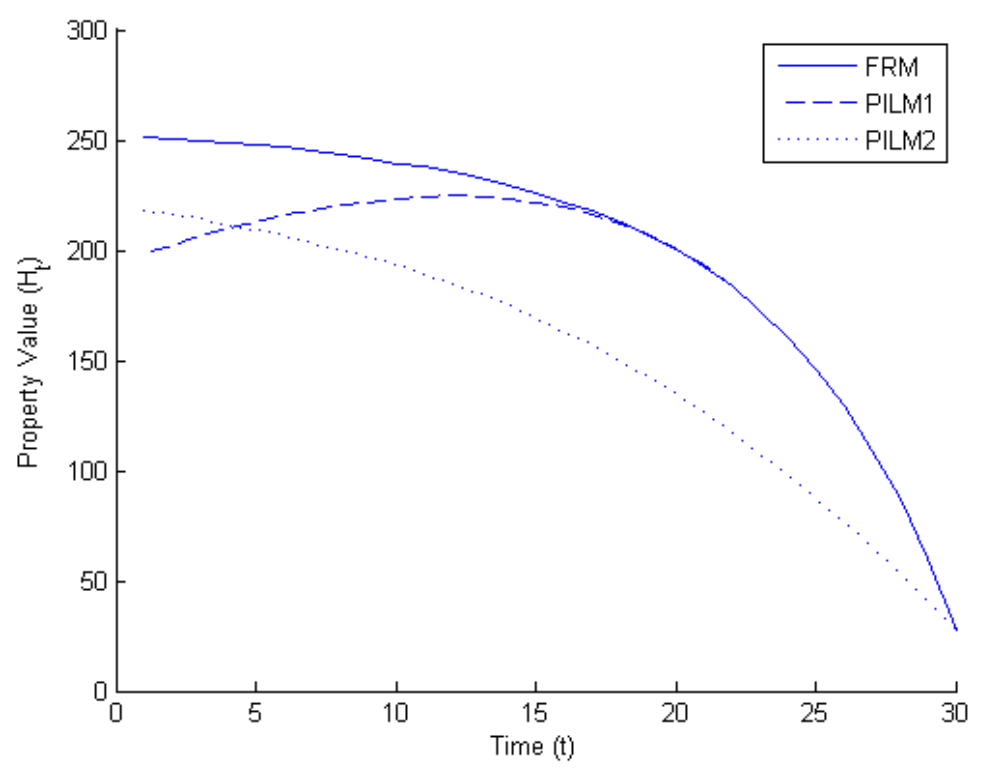

Figure 4: The default boundaries of the three mortgage contracts over time, calculated under the assumptions that $\mathrm{MR}_{t}=\mathrm{MR}_{0}=0.05, \mathrm{ER}_{t}=\mathrm{ER}_{0}=0.05$ and $M_{t}=24.72$ for all $t>0$.

for the three mortgage contracts.

First, the default boundaries for the two PILMs are lower than or the same as that for the FRM, indicating that overall the PILM borrowers have a lower propensity to default. This result is expected, because the PILM borrowers are partially compensated by a loan adjustment in the event of a substantial drop in house price.

Second, the default boundary for the PILM2 is higher than that for the PILM1 during the first four years, and reduces steadily over time. The former outcome can be explained by the fact that in early mortgage years a PILM1 loan adjustment tends to be more pronounced. The latter outcome can be attributed to the fact that towards the end of the mortgage term, the number of outstanding payments is small but the likelihood of a PILM2 loan adjustment does not diminish (as it comes into effect whenever the property value is lower than $H_{0}$ ).

Third, the default boundary for the PILM1 increases with time in the first 12 years and subsequently converges to the FRM's default boundary. The variation in the PILM1's default boundary over time arises from the following two forces that are acting in opposite directions: (1) as the borrower builds equity in the property, he/she is less likely to default; (2) the default option becomes more attractive than the other two options as the loan balance reduces, because the opportunity to receive loan adjustments becomes smaller (a PILM1 loan adjustment is triggered only when $H_{t}$ is less than $U_{t}$, which decreases over time) and the option to refinance is less valuable. In this example, the effect of (2) is greater than that of (1) over the first 12 mortgage years, leading to a rise in the PILM1's default boundary. Approaching the end of the mortgage term, a PILM1 adjustment becomes more difficult to be triggered and even if it is triggered the extent tends to be small. For this reason, as $t \rightarrow T$, the PILM1 becomes literally identical to the FRM and thus has a default boundary that is close to the FRM's.

In a similar manner, we can also study a mortgage contract's refinancing boundary, the 


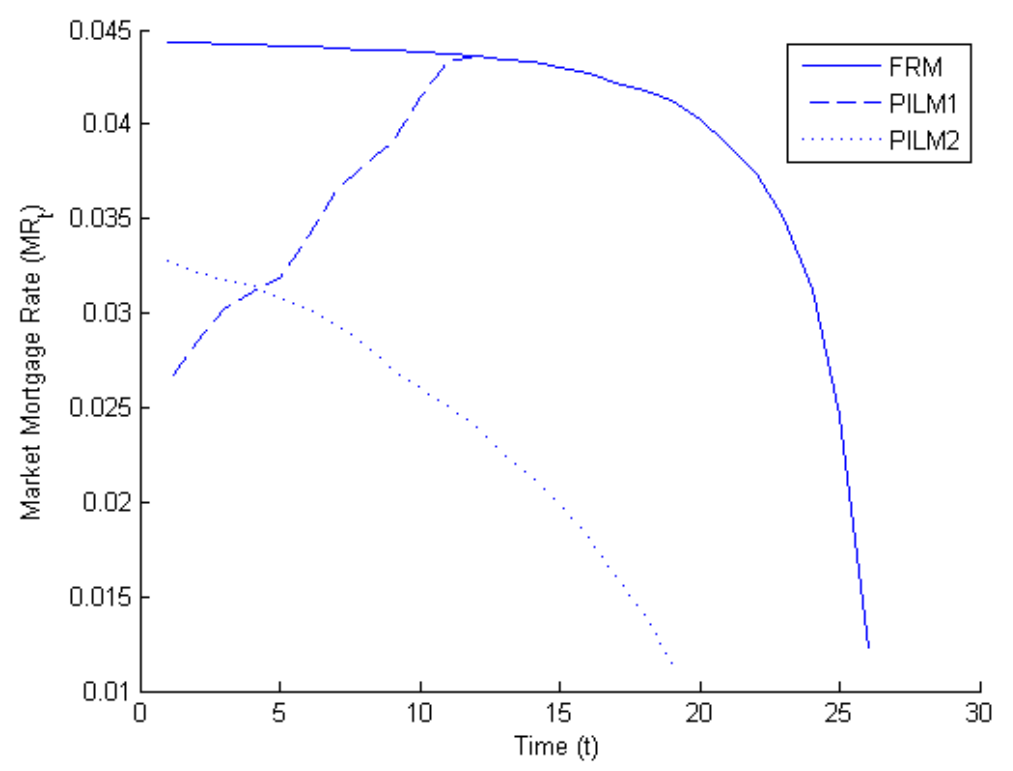

Figure 5: The refinancing boundaries of the three mortgage contracts over time, calculated under the assumptions that $H_{t}=300, \mathrm{ER}_{t}=\mathrm{ER}_{0}=0.05$ and $M_{t}=24.72$ for all $t>0$.

highest mortgage rate at which the borrower finds it optimal to refinance. The refinancing boundary for a PILM depends on the current and potential future loan adjustments. The higher the adjustments are, the lower market mortgage rate is required to make refinancing sufficiently attractive, thereby resulting in a lower refinancing boundary. In Figure 5 we show the refinancing boundaries, calculated at a fixed house price of 300, for the three mortgage contracts over time. It can be seen that the refinancing boundaries have similar patterns as the default boundaries. The explanations to the patterns of the default boundaries also apply to the patterns of the refinancing boundaries.

\subsection{Lender's Valuation}

Thus far we have just considered the borrower's perspective. We have seen that the PILM contracts lead to lower mortgage payments when house prices fall and hence a lower default propensity relative to the standard FRM. Indeed this is the justification for the PILMs in the first place. However for the PILM contracts to be viable they need to be offered in the market place. Hence we need to value these contracts from a lender's perspective. To do so we project the cash flows assuming optimal borrower behaviour and include the deadweight costs suffered by the lender upon default. These costs are described in detail by Brueggeman and Fisher [9] and Qi and Yang [33]. We obtain the lender's valuation of the loan by taking the expected net present value of its cash flows under a given mortgage contract at an appropriate discount rate. We use Monte Carlo simulation to estimate these expected values.

We rank the different contracts from the viewpoint of each party. In the case of the borrower we compute the expected utility under each contract and convert it to a level stream of consumption. The borrower will prefer a higher consumption stream to a lower one. In the case of the lender we calculate the discounted value of its expected cash flows under the mortgage. 


\begin{tabular}{|l|c|c|c|}
\hline & FRM & PILM1 & PILM2 \\
\hline Cumdef (\%) & 15.76 & 12.87 & 4.38 \\
\hline EC & 56.84 & 57.16 & 57.48 \\
\hline WG $^{\mathrm{B}}(\%)$ & - & 0.57 & 1.12 \\
\hline APV & 380 & 379.88 & 382.13 \\
\hline WG $^{\mathrm{L}}(\%)$ & - & -0.03 & 0.56 \\
\hline
\end{tabular}

Table 2: Summary of results of default incidence, mortgage valuation and welfare gains. 'Cumdef' represents the cumulative probability of default at the end of the loan term, 'EC' represents the equivalent constant consumption, ' $\mathrm{WG}^{\mathrm{B}}$ ' represents the borrower's welfare gain, 'APV' represents the average present value of the lender's cash flows, and ' $\mathrm{WG}^{\mathrm{L}}$ ' represents the lender's welfare gain.

We find that for a range of plausible parameters both parties prefer the PILM contract so the contract design is Pareto improving in these circumstances.

We also show that the cumulative defaults are significantly lower under the PILM mortgages than under the traditional FRM mortgage. Mortgage defaults have spillover effects (Mian et al. [32], Bradley et al. [8]), impose social costs (Andritzky [4]), and thus to the extent that these new designs reduce defaults this is another advantage.

We generate 10,000 economic scenarios, each of which contains one path of property values and one path of market mortgage rates. For each simulated scenario, we derive the borrower's optimal actions, compute the borrower's utility and calculate the borrower's consumption and the lender's cash flows at different time points. The results are reported in Table 2.

Consistent with our earlier results, we find that a payment adjustment feature can significantly reduce the cumulative probability of default at the end of the loan term (Cumdef). We refer a PILM default to as a 'direct' default if refinancing has never occurred before and an 'indirect' default if it happens after the mortgage is refinanced into a FRM. In our simulation, about $38 \%$ of the PILM1 defaults and $40 \%$ of the PILM2 defaults are indirect. The default probabilities reported in Table 2 incorporate both direct and indirect defaults.

We define the equivalent consumption (EC) for contract $k$ as the constant level of consumption $C^{k}$ that yields a time-0 utility that equals $J_{0}^{k}$; that is,

$$
\sum_{t=0}^{T_{L}} \beta^{t} U\left(C^{k}\right)=J_{0}^{k}, \quad k \in\{\text { FRM, PILM1, PILM2 }\}
$$

From the simulations, we can estimate $J_{0}^{k}$ and hence $C^{k}$. We interpret the percentage difference between the ECs of a PILM and the corresponding FRM as the borrower's welfare gain $\left(\mathrm{WG}^{\mathrm{B}}\right.$ ) should he/she choose the PILM instead of the FRM. The values of $\mathrm{WG}^{\mathrm{B}}$ are positive for both PILM contracts. This result is expected, because it is assumed that the loan adjustment feature is provided to the PILM borrowers at no cost $(\mathrm{RS} 1=\mathrm{RS} 2=0)$.

We calculate the average present value (APV) of the lender's cash flows, using a varying discount rate that equals the prevailing market mortgage rate less $0.88 \%$. The spread of $0.88 \%$ is chosen in such a way that the average present value of the FRM lender's cash flows equals 
the initial loan amount. It is assumed in the calculations that the lender recovers a net amount of $\mathrm{RR}=50 \%$ of the (reference) loan balance upon default. ${ }^{20}$ We interpret the percentage difference between the APVs of a PILM and the corresponding FRM as the lender's welfare gain $\left(\mathrm{WG}^{\mathrm{L}}\right)$ should he/she write the PILM rather than the FRM. The value of $\mathrm{WG}^{\mathrm{L}}$ for the PILM1 is close to zero, while that for the PILM2 is positive. This result indicates that the saving arising from the reduction in default and hence foreclosure costs is (more than) enough to cover the cost arising from the potential loan adjustments.

\section{Robustness Checks to Input Parameters}

In this section we examine the sensitivity of the results to different input parameters. This exercise provides deeper insight into the model and enables us to assess the importance of different parameters. It proves convenient to categorize the baseline parameters into four groups. These groups correspond to the borrower's characteristics, mortgage and rental markets, mortgage contract characteristics and housing and interest rate dynamics. We compute the various items of interest in Table 2 under a range of different input parameters by varying the baseline assumptions one at a time. For each of our three mortgage contracts we compute the cumulative default probability, the equivalent level consumption and the lender's valuation. This information enables us to rank the contracts from both the borrower's and lender's perspectives and also provides a comparison with the baseline results.

Table 3 reports, for each mortgage contract, the values of Cumdef, EC and APV that are calculated on the basis of alternative parameter values. This table also shows the welfare gains to the borrower and lender when a PILM is used instead of a FRM. To ensure comparability against the baseline results, here we also discount the lender's cash flows at the prevailing market mortgage rate less $0.88 \%$.

When interpreting the results, readers should keep in mind that EC and APV are only measures of the overall behaviour and welfare. That being said, even if the values of EC and APV under an alternative assumption are very close to their baseline values, the patterns of the borrower's behaviour, the borrower's consumption and/or the lender's cash flows could still be very different.

\footnotetext{
${ }^{20}$ The recovery rates of FHA loans are in between $40 \%$ and $60 \%$. Source: Exhibit E-2 of the FHA Actuarial Review [25].
} 


\begin{tabular}{|c|c|c|c|c|c|c|c|c|c|c|c|c|c|c|c|}
\hline של & $\left|\begin{array}{l}0 \\
0 \\
0 \\
0\end{array}\right|$ & 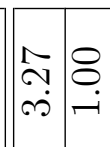 & 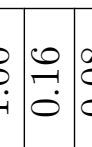 & \begin{tabular}{l|l}
$\infty$ \\
$\stackrel{8}{8}$ \\
\hdashline
\end{tabular} & & $\mathscr{\mathscr { C }}$ & $\mid$\begin{tabular}{l}
$\mathcal{N}$ \\
\hdashline \\
0
\end{tabular} & $\stackrel{م}{\circ}$ & $\left|\begin{array}{l}\hat{\imath} \\
\hat{C} \\
1\end{array}\right|$ & 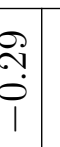 & $\stackrel{\overparen{b}}{0}$ & $\stackrel{8}{0}$ & 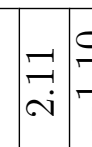 & $\begin{array}{l}\infty \\
\infty \\
\sim \\
i\end{array}$ & $\begin{array}{l}\stackrel{n}{*} \\
0 \\
1\end{array}$ \\
\hline$\vec{z}$ & 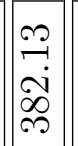 & 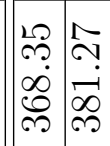 & 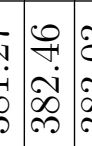 & & & & 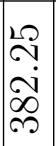 & 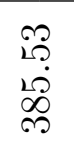 & & 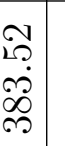 & 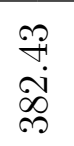 & $\begin{array}{l}\stackrel{0}{1} \\
\stackrel{1}{\infty} \\
\stackrel{0}{\infty}\end{array}$ & 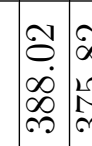 & $\begin{array}{l}\vec{\sigma} \\
\dot{b} \\
\infty \\
\infty \\
\infty\end{array}$ & $\begin{array}{l}\infty \\
\infty \\
\stackrel{\jmath}{\exists} \\
\forall\end{array}$ \\
\hline $\overrightarrow{0}$ & $\stackrel{2}{\stackrel{2}{\sim}}$ & 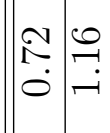 & 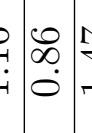 & & & ᄃ & $\vec{\exists}$ & 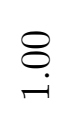 & & \begin{tabular}{l}
$\Re$ \\
\hdashline \\
\hdashline
\end{tabular} & $\stackrel{\vec{\infty}}{0}$ & $\stackrel{8}{\circ}$ & 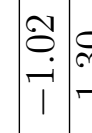 & $\stackrel{\mathscr{\leftrightarrow}}{\leftrightarrow}$ & $\vec{\sigma}$ \\
\hline 㽞 & 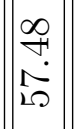 & 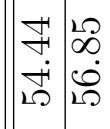 & 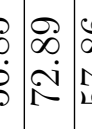 & 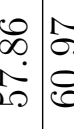 & $\left\{\begin{array}{l}1 \\
7 \\
1 \\
1\end{array}\right.$ & & 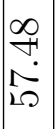 & $\begin{array}{l}\text { Iै } \\
\text { ه. }\end{array}$ & & 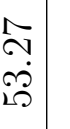 & 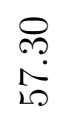 & \begin{tabular}{l}
8 \\
\multirow{6}{0}{} \\
L.
\end{tabular} & 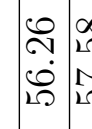 & $\underset{\text { 곤 }}{\stackrel{7}{2}}$ & $\begin{array}{l}\overline{6} \\
\ddot{\theta}\end{array}$ \\
\hline 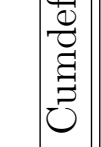 & 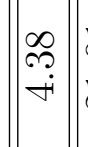 & 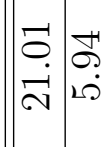 & 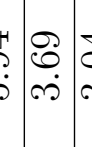 & & & & 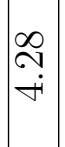 & : & & $\begin{array}{l}0 \\
+ \\
i \\
i\end{array}$ & $\stackrel{\vec{\rho}}{\stackrel{n}{\wedge}}$ & $\underset{\mathrm{i}}{\stackrel{ }{\mathrm{i}}}$ & 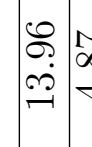 & مُ & \\
\hline
\end{tabular}

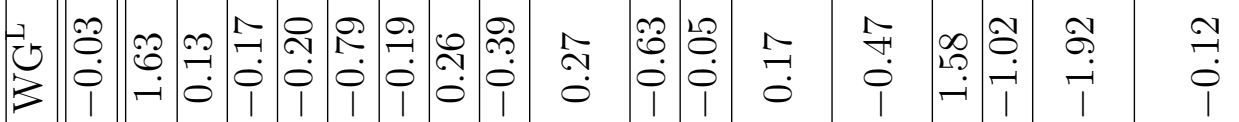

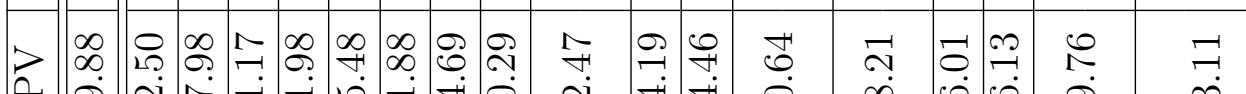

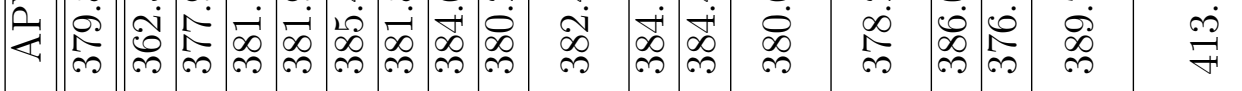

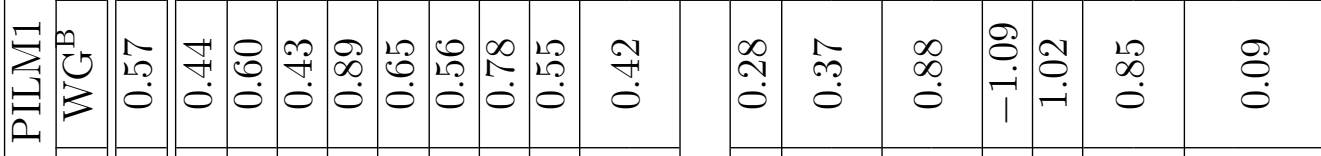

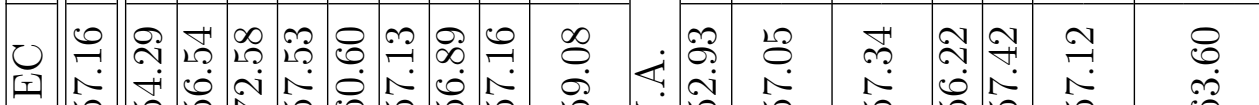

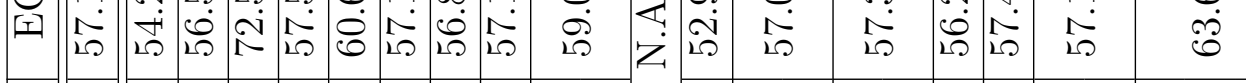

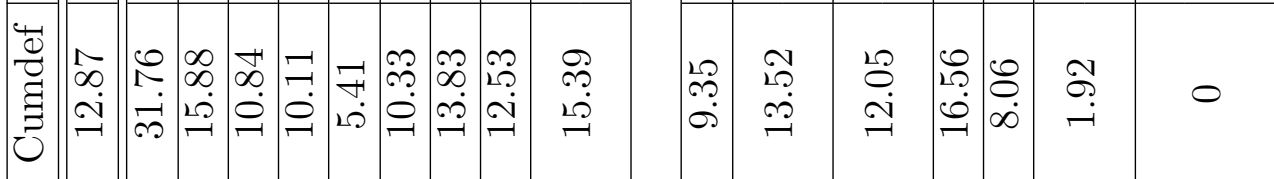

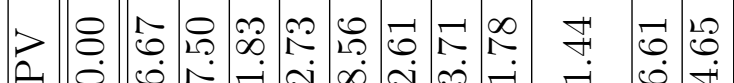

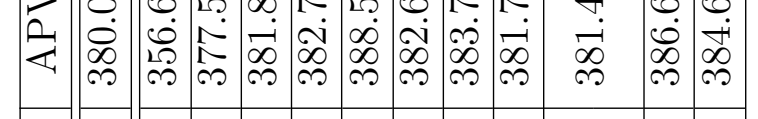

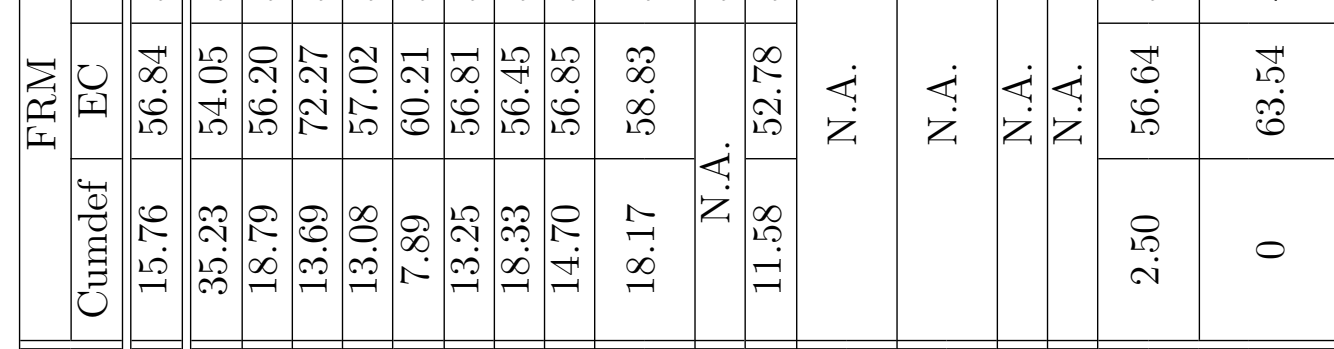

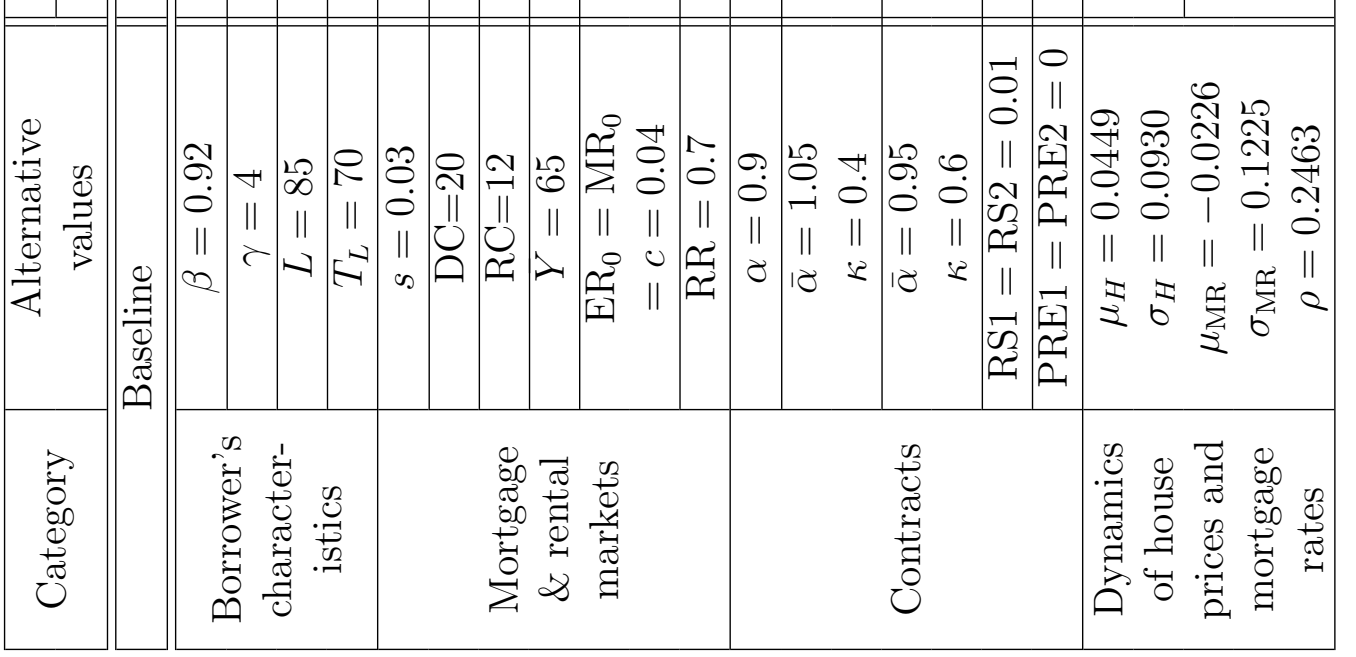

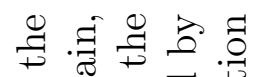

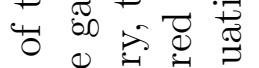
च

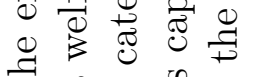

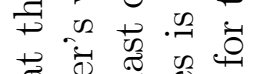

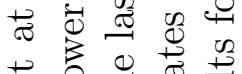

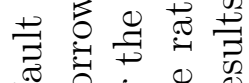
苟 넝 ․ कृ च

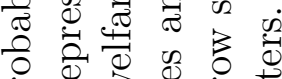

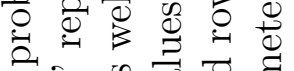
क क क च

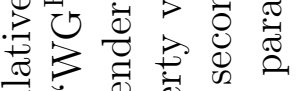
5 . 0

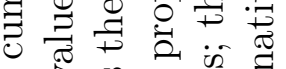
용 क

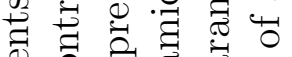
ర్ర

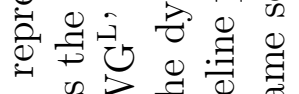
案.

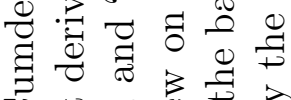
U w w

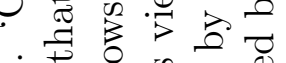
क्ष 记 $\overrightarrow{0}$

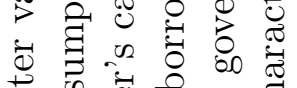
के ज्ञ

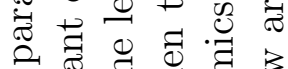

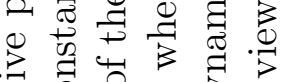
웡 0 o

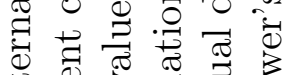
证

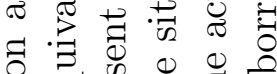
- $\mathbb{O}^{2}$ 证 0 踏

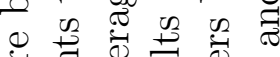

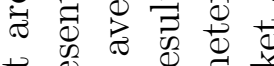

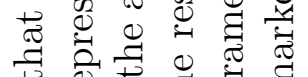

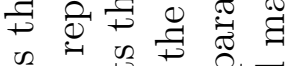

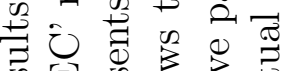

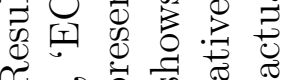

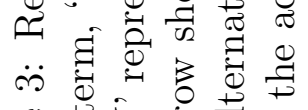
임

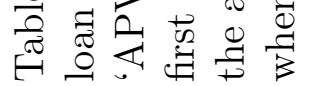




\subsection{Sensitivity to the Borrower's Characteristics}

We begin with the borrower's time preference of consumption, represented by the utility discount parameter $(\beta)$. A smaller $\beta$ implies that the borrower is less patient as future consumption is discounted more heavily. When $\beta$ decreases from 0.96 to 0.92 , the default probabilities for all contracts are more than twice their corresponding baseline estimates. We can explain the change in default propensity by considering the benefit and cost of default. Since a necessary condition for default is that the prevailing market rent is cheaper than the current loan payment, default increases the borrower's current consumption as it substitutes the current loan payment with a relatively cheaper rent. On the other hand, default decreases the borrower's future consumption, because after default the borrower has to pay rent until he/she dies. At the baseline default boundary, the benefit and cost arising from default exactly offset each other. However, when $\beta$ becomes smaller than its baseline value, the benefit outweighs the cost, because the borrower weights his/her current consumption more than his/her future consumption. In other words, a borrower with a smaller $\beta$ should prefer to default at the baseline default boundary, implying that the default boundary for him/her is higher than that for the baseline borrower. Hence, regardless of the contract type, a less patient borrower has a higher propensity to default.

As the primary objective of the loan adjustment feature in a PILM is to reduce the borrower's incentive to default, it is reasonable to conjecture that from the lender's perspective the advantage of PILMs over the corresponding FRM is more profound when the borrower (in the absence of any loan adjustment feature) has a higher propensity to default. This conjecture is confirmed in the sensitivity analysis. When $\beta$ reduces from 0.96 to 0.92 , the FRM borrower has a significantly higher propensity to default (Cumdef increases from $15.76 \%$ to $35.23 \%$ ). At the same time, the values of $\mathrm{WG}^{\mathrm{L}}$ for both PILM1 and PILM2 increase significantly, indicating that the advantage of the loan adjustment feature to the lender becomes more prominent.

When $\gamma$ increases from 3 to 4 , the values of Cumdef for all contracts increase, suggesting that a higher risk aversion means a higher propensity to default. This outcome can be understood by comparing the levels of risk that borrowers and renters face. According to our set-up, the only risk that a renter faces is the uncertainty associated with rent. This uncertainty is related exclusively to house price risk and is in principle limited due to the cap $\bar{Y}$ imposed. By contrast, all borrowers bear the risk associated with ownership benefit plus the uncertainty arising from potential default and refinancing in the future. Also, a PILM borrower is subject to the added uncertainty arising from potential loan adjustments. Hence, compared to a renter, a borrower is subject to more sources of risk. Consequently, as risk aversion increases, one would be more likely to default and rent than to repay or refinance. We also observe that the increase in Cumdef (due to the increase in $\gamma$ ) comes with an increase in $\mathrm{WG}^{\mathrm{L}}$. This observation is again in line with the conjecture that the benefit of loan adjustments to the lender is more prominent when the borrower has a higher propensity to default.

For all three mortgage contracts, an increase in income $(L)$ raises the borrower's consumption at every future date by a fixed amount, thereby providing the borrower with a higher 
level of expected utility irrespective of whether he/she chooses to default or not. This fact is the major reason for the increase in the equivalent consumption (EC) of all borrowers as $L$ increases from 70 to 85 . We also observe that when $L$ increases, the default probabilities for all three contracts decrease. This observation indicates that an increase in $L$ benefits those who choose not to default more than those who choose to. It also agrees with our intuition that a person with a higher income is less likely to default. Furthermore, $\mathrm{WG}^{\mathrm{L}}$ becomes lower as the default propensity reduces, in line again with the previously mentioned relationship between default propensity and the advantage of the loan adjustment feature to the lender.

When the borrower's remaining lifespan $\left(T_{L}\right)$ increases from 60 to 70, his/her default propensity reduces. This outcome can be explained as follows. A larger $T_{L}$ increases the number of periods (beyond time $T$ ) over which an individual can consume, thereby increasing the bequests for both homeowners and renters. However, because homeowners always enjoy higher consumption than renters after time $T$, the increase in the bequest for homeowners are higher than that for renters. As a result, homeownership becomes more attractive and the incentive to default reduces.

\subsection{Sensitivity to the Mortgage and Rental Market Parameters}

We next examine the sensitivity of the results to the mortgage and rental market parameters. When the ownership benefit rate $(s)$ increases from $2 \%$ to $3 \%$, the total defaults for all contracts are significantly reduced. We obtain this result because an increase in $s$ raises homeowners' consumption in all states of the world but not the renters', thereby making default (i.e., forfeiting homeownership) less attractive. When $s$ is increased to 3\%, the FRM borrower's default propensity becomes so low that the provision of loan adjustments is no longer advantageous to lenders (the values of $\mathrm{WG}^{\mathrm{L}}$ for both PILMs are significantly below zero). This result means that when the ownership benefit rate is high, the reduction in foreclosure costs due to lower default rates may not be sufficient to cover the cost of loan adjustments. In this case, the PILM lender may consider using a less extensive adjustment scheme or charging a spread over the corresponding FRM. ${ }^{21}$

When the default cost (DC) increases from 10 to 20, the default probabilities for all contracts decrease. This result can be attributed to the fact that a higher DC reduces the consumption when default takes place. The increase in $\mathrm{DC}$ also comes with a decrease in $\mathrm{WG}^{\mathrm{L}}$, because, as we explained earlier, the benefit of loan adjustments to the lender should be less substantial when the borrower has a smaller propensity to default.

The effect of a change in the refinancing cost $(\mathrm{RC})$ depends on the contract design. For a FRM contract, a higher RC decreases the values of refinancing and the option to refinance, but has no direct effect on the value of default. Consequently, default becomes more attractive and thus the borrower's propensity to default increases. This relationship is confirmed in our results, which show that when RC increases from 6 to 12, the value of Cumdef for the FRM increases from $15.76 \%$ to $18.33 \%$. For a PILM contract, an increase in RC has two opposing

\footnotetext{
${ }^{21}$ The impact of charging a positive spread is detailed in Section 5.3.
} 


\begin{tabular}{|c|c|c|c|c|c|c|}
\hline \multirow{2}{*}{} & \multicolumn{3}{|c|}{ PILM1 } & \multicolumn{3}{c|}{ PILM2 } \\
\cline { 2 - 7 } & Direct & Indirect & Total & Direct & Indirect & Total \\
\hline $\mathrm{RC}=6$ & 799 & 488 & 1287 & 264 & 174 & 438 \\
\hline $\mathrm{RC}=12$ & 1118 & 265 & 1383 & 291 & 53 & 344 \\
\hline
\end{tabular}

Table 4: The number of direct defaults, the number of indirect defaults and the total number of defaults (out of the 10,000 simulated scenarios) for each of the PILM contracts. The values are calculated at a refinancing cost of 6 (the baseline assumption) and 12 (the alternative assumption).

\begin{tabular}{|c|c|c|c|c|c|c|}
\hline \multirow{2}{*}{} & \multicolumn{2}{|c|}{ FRM } & \multicolumn{2}{c|}{ PILM1 } & \multicolumn{2}{c|}{ PILM2 } \\
\cline { 2 - 7 } & \# of scenarios & Total \# & \# of scenarios & Total \# & \# of scenarios & Total \# \\
\hline $\mathrm{RC}=6$ & 7249 & 14312 & 7286 & 14245 & 5183 & 9561 \\
\hline $\mathrm{RC}=12$ & 5107 & 6604 & 5299 & 6657 & 3198 & 3858 \\
\hline
\end{tabular}

Table 5: "\# of scenarios" shows the number of scenarios (out of the 10,000 simulated scenarios) in which the borrower refinances at least once and "Total \#" shows the total number of refinancing in all simulated scenarios for each of the three contracts. The values are calculated at a refinancing cost of 6 (the baseline assumption) and 12 (the alternative assumption).

effects on the borrower's propensity to default. On one hand, it makes direct default more attractive. On the other hand, it reduces the borrower's propensity to refinance into a FRM, which has a higher default boundary compared to a PILM, thereby leading to a reduction in indirect defaults. The relative strengths of these two offsetting effects determine the change in the overall default probability. In this analysis, the former effect is stronger for the PILM1 but weaker for the PILM2 (see Table 4). As a result, the value of Cumdef for the PILM1 increases but that for the PILM2 decreases.

It is interesting to note that the when $\mathrm{RC}$ increases, the values of $\mathrm{APV}$ for all contracts increase noticeably, even though the default probabilities for the FRM and PILM1 contracts are higher. This interesting outcome may be attributed to the reduced propensity to refinance. From Table 5 we observe that when RC increases from 6 to 12, the borrowers refinance in fewer scenarios and the total number of refinancing for each contract is substantially reduced. Because a necessary condition for refinancing is lower mortgage payments, the less often the borrowers refinance, the larger amount of payments would be received by the lenders. If the effect of a reduced propensity to refinance outweighs the (opposite) effect of a larger propensity to default, then the cash flows to the lender and hence the value of APV would increase. From this example, we can tell that for a given contract, a higher default probability does not necessarily imply a lower APV.

When the rent cap $(\bar{Y})$ increases from 25 to 65 , the default probabilities for all three contracts decrease slightly. The decrease in default probabilities is expected, because a higher $\bar{Y}$ means that renters are subject to more risk and hence default becomes relatively less attractive. The decrease in default probabilities is quite small, because the property values at the default boundary are much lower than the property values that would result in a rent of $\bar{Y}$.

Next we consider the situation when the initial market mortgage rate $\left(\mathrm{MR}_{0}\right)$, the initial effective rate $\left(\mathrm{ER}_{0}\right)$ and the rent-to-price ratio $(c)$ are all reduced by $1 \%$. The reduction in 
these parameters has two opposite effects on the borrower's propensity to default. First, a lower effective rate reduces the borrower's mortgage payments and hence makes continuing to repay more attractive. Second, a lower rent-to-price ratio reduces rents hence increases the attractiveness of default. The results indicate that the latter effect is stronger, as the values of Cumdef for all three contracts become higher. Because the reduction in $\mathrm{MR}_{0}, \mathrm{ER}_{0}$ and $c$ increases consumption regardless of homeownership, the values of EC for all three contracts are higher.

Finally, when the recovery rate (RR) increases from $50 \%$ to $70 \%$, the default costs are reduced and hence the average present value of the cash flows to the lender increases. The increase is the most significant to the FRM lender, because it faces the highest default probability. As RR increases, the benefit arising from the loan adjustment feature that aims to reduce default propensity becomes less significant. When $\mathrm{RR}=70 \%$, the values of $\mathrm{WG}^{\mathrm{L}}$ for both PILMs become negative, indicating that with this recovery rate the benefit cannot cover the cost of loan adjustments. Note that a change in the recovery rate has no impact on the borrower's behaviour or utility.

\subsection{Sensitivity to the Mortgage Contract Parameters}

This subsection examines the sensitivity of the results to the mortgage contract parameters. We start with the initial LTV $(\alpha)$. When $\alpha$ reduces from 0.95 to 0.9 , all borrowers have a lower propensity to default. This is because a lower $\alpha$ corresponds to a smaller initial loan balance, which leads to smaller mortgage payments for all contracts. ${ }^{22}$ However, a change in $\alpha$ has no impact on rents. Hence, when $\alpha$ decreases, default becomes relatively less attractive and the propensity to default reduces. Furthermore, in line with our conjecture that the benefit of loan adjustments to the lender is less substantial when the borrower has a lower propensity to default, we observe that the values of $\mathrm{WG}^{\mathrm{L}}$ for both PILMs become smaller (and negative) as $\alpha$ reduces.

When $\alpha$ reduces from 0.95 to 0.9 , all borrowers have lower equivalent consumptions. The decrease in EC can be attributed to two reasons. First, as $\alpha$ becomes smaller, there is a shift of consumption from $t=0$ to $t=1, \ldots, T$, thereby resulting in a decrease in EC as intertemporal utility discount applies to the consumptions beyond time 0. Second, because the initial loan balance reduces, the borrower's potential benefits arising from refinancing, default and loan adjustments are less significant. ${ }^{23}$

Next, we consider parameters $\bar{\alpha}$ and $\kappa$ in the PILM adjustment schemes. According to the specifications of the adjustment schemes, a lower target LTV $(\bar{\alpha})$ makes a PILM1 loan adjustment easier to be triggered, while a higher workout proportion $(\kappa)$ increases the extent

\footnotetext{
${ }^{22} \mathrm{~A}$ reduction in $\alpha$ implies a decrease in FRM and PILM2 mortgage payments in all states of the world, because FRM payments are proportional to $\alpha$ and are fixed at origination while PILM2 loan payments (both adjusted and unadjusted) are proportional to $\bar{M}$ (which is in turn proportional to $\alpha$ ). A reduction in $\alpha$ implies a decrease in PILM1 mortgage payments at times when no loan adjustment is triggered.

${ }^{23}$ In practice the borrower may prefer a higher down payment as it lowers the borrower's contract rate and/or mortgage insurance premium. These benefits may outweigh the utility loss due to consumption shifting and reduced option values, but are not considered in our partial equilibrium framework.
} 


\begin{tabular}{|c|c|c|c|c|c|c|c|}
\hline & \multirow{2}{*}{ FRM } & \multicolumn{3}{|c|}{ PILM1 } & \multicolumn{3}{c|}{ PILM2 } \\
\cline { 3 - 8 } & & Direct & Indirect & Total & Direct & Indirect & Total \\
\hline RS1 $=$ RS2 $=0$ & \multirow{2}{*}{1576} & 799 & 488 & 1287 & 264 & 174 & 438 \\
\cline { 3 - 8 } & & 348 & 1308 & 1656 & 343 & 1053 & 1396 \\
\hline
\end{tabular}

Table 6: The number of defaults (out of the 10,000 simulated scenarios) for each of the three contracts. For each PILM, the specific numbers of direct and indirect defaults are also shown. The values are calculated at $\mathrm{RS} 1=\mathrm{RS} 2=0$ (the baseline assumption) and $\mathrm{RS} 1=\mathrm{RS} 2=0.01$ (the alternative assumption)

\begin{tabular}{|c|c|c|c|}
\hline & FRM & PILM1 & PILM2 \\
\hline $\mathrm{RS} 1=\mathrm{RS} 2=0$ & \multirow{2}{*}{5252} & 4817 & 2966 \\
\cline { 1 - 3 } \cline { 3 - 4 } $\mathrm{RS} 1=\mathrm{RS} 2=0.01$ & & 9021 & 8211 \\
\hline
\end{tabular}

Table 7: The number of scenarios (out of the 10,000 simulated scenarios) in which the borrower refinances at least once in the first 5 years of the mortgage term for each of the three contracts. The values are calculated at $\mathrm{RS} 1=\mathrm{RS} 2=0$ (the baseline assumption) and $\mathrm{RS} 1=\mathrm{RS} 2=0.01$ (the alternative assumption),

of a PILM2 loan adjustment if it is triggered. When loan adjustments are easier to trigger and/or stronger if triggered, PILM borrowers should have a lower propensity to default and higher welfare. The relationship is confirmed in our simulation results. For the PILM1, when $\bar{\alpha}$ rises from 1 to 1.05, Cumdef increases but EC decreases; for the PILM2, when $\kappa$ increases from 0.5 to 0.6 , Cumdef falls but EC rises. The exact opposite is true when $\bar{\alpha}$ reduces from 1 to 0.95 and $\kappa$ decreases from 0.5 to 0.4 . To the lenders, a lower $\bar{\alpha}$ or a higher $\kappa$ means more benefits arising from the reduction in default costs but higher costs of loan adjustments. Table 3 shows that the values of APV for both PILM lenders become lower when $\bar{\alpha}$ decreases and $\kappa$ increases, indicating that the latter effect outweighs the former.

We next move to sensitivity testing the mortgage rate spreads between the PILMs and the FRM. When the rate spreads RS1 and RS2 increase from $0 \%$ to $1 \%$ (i.e., the contract rate of the PILMs increases from 5\% to 6\%), the PILMs' default probabilities rise dramatically. From Table 6, which displays the breakdown of PILM defaults under the baseline and alternative rate spread assumptions, we observe that the increase in default probabilities is due primarily to the increase in indirect defaults. Moreover, it can be seen from Table 7 that at the higher rate spread most of the PILM borrowers refinance during the first 5 years of the mortgage term. As the PILM borrowers tend to refinance (into a FRM) in early years, it is not surprising that the default probabilities for the PILM borrowers become close to that of the FRM borrowers. It is also worth noticing that $\mathrm{WG}^{\mathrm{B}}$ becomes negative while $\mathrm{WG}^{\mathrm{L}}$ becomes strictly positive. We may therefore view a positive rate spread as a means to transfer welfare from borrowers to lenders.

Finally, we examine the consequences of setting the prepayment penalty parameters (PRE1 and PRE2) to zero. The effects of having a zero prepayment penalty are threefold. First, when the prepayment penalty is waived, the values of refinancing and the option to refinance increase, because the PILM borrowers are able to lock in the low post-adjustment loan balance at no cost if they refinance. As a result, the values of continuing and refinancing increase, 
leading to a reduction in direct defaults. Second, as the borrower's propensity to refinance rises, the probability of an indirect default tends to increase. Third, without any prepayment penalty, the borrower is able to lock in the loan balance at a time when the loan adjustment is very substantial. A smaller loan balance at the moment of refinancing tends to reduce the probability of an indirect default. The overall impact on the default probability depends on the relative strengths of these three effects. Table 3 shows that reducing the prepayment penalty to zero results in a substantial decrease in the PILM1 default probability but a slight increase in the PILM2 default probability. Again, we may regard the prepayment penalty as a means to transfer welfare between lenders and borrowers, since the removal of prepayment penalty increases the borrowers' welfare but decreases the lenders'.

In this sensitivity analysis, we see that a change in the value of contract-related parameter tends to have opposite effects on the borrower's and lender's welfare. Because the values of these parameters are negotiable, they can be used to adjust the allocation of the welfare gain arising from the loan adjustment feature between the borrower and lender. If we assume that the mortgage market is perfectly competitive and that all lenders are risk-neutral, then the PILM1 (PILM2) contract that would be offered in the market should be the one with parameters $\bar{\alpha}$, RS1 and PRE1 ( $\kappa$, RS2 and PRE2) that would result in $\mathrm{WG}^{\mathrm{L}}=0$. The problem of PILM pricing then boils down to the calculation of such parameters.

\subsection{Sensitivity to the Parameters in the House Price and Mortgage Rate Processes}

We conclude this section by analyzing the impact of changes in the parameters that are associated with the dynamics of house prices and mortgage rates. We first estimate the parameters in the processes for $H_{t}$ and $\mathrm{MR}_{t}$ on the basis of the historical annual log-returns on the monthly S\&P/Case-Shiller 10-City Composite Home Price Index and the conventional conforming 30-year FRM mortgage rates, respectively. ${ }^{24}$ The estimation results $\left(\mu_{H}=0.0449, \sigma_{H}=\right.$ $\left.0.0930, \mu_{\mathrm{MR}}=-0.0226, \sigma_{\mathrm{MR}}=0.1225, \rho=0.2463\right)$ indicate that over the calibration window, house prices were rising but mortgage rates were decreasing on average.

Throughout the following analysis, we assume that each borrower's view on the property and mortgage markets is always consistent with the calibrated parameters. The borrowers considered here are more optimistic compared to the baseline borrowers, since an upward expected trend in property values (characterized by a positive value of $\mu_{H}$ ) increases ownership benefit and bequest while a downward trend in mortgage rates (captured by a negative value of $\mu_{\mathrm{MR}}$ ) reduces mortgage payments if the loan is refinanced. The realized behaviour and welfare of a borrower depend on the real property and mortgage markets. Two different cases concerning the real markets are considered.

\footnotetext{
${ }^{24}$ We consider data over the period from Oct 1992 to Feb 2014. The house price index is available at http: //ca.spindices.com/indices/real-estate/sp-case-shiller-10-city-composite-home-price-index. The mortgage rates are obtained from the Freddie Mac Primary Mortgage Market Survey, available at http://www.freddiemac.com/pmms/pmms_archives.html.
} 
In the first case, we assume the real markets are represented by the baseline processes for $H_{t}$ and $\mathrm{MR}_{t}$ (with $\mu_{H}=\mu_{\mathrm{MR}}=0$ ). This assumption implies that the borrowers are mistakenly optimistic, which in turns leads to suboptimal behaviour. Because the overly optimistic borrowers do not default when it is actually optimal to default, the default probabilities for all contracts become very low. As default risk reduces, the welfare of all lenders (represented by APV) increases. The PILM lenders' welfare increases less significantly than the FRM lender's. This is because as the borrower's propensity to default reduces, the loan adjustment feature in a PILM becomes more likely to be triggered and hence more costly, thereby offsetting the benefit arising from the reduction in default risk.

In the second case, we assume that both the real markets and the markets perceived by the borrowers are characterized by the calibrated parameters. Under this assumption, the default probabilities further reduce (to zero). This is because under the current assumption $H_{t}$ and $\mathrm{MR}_{t}$ are more likely to drift to values at which the action of default is not optimal, but the borrowers' decision rules (which are based on their perceived markets) remain unchanged. The borrowers' welfare (represented by EC) increases, because of an upward trend in the actual property values and a downward trend in the actual mortgage rates. In terms of Cumdef, EC and APV, the three mortgage contracts look similar to one another. The similarity is in part because when $\mu_{H}=0.0449$ the simulated property values are so high that PILM loan adjustments are seldom triggered, and in part because when $\mu_{\mathrm{MR}}=-0.0226$ the simulated mortgage rates are so low that most PILM borrowers refinance their loans (into FRMs) in early years.

\section{Conclusion}

The 2008-2009 financial crisis saw a dramatic increase in mortgage defaults. The once thought to be the safest mortgage instrument - fixed rate mortgage (FRM) - experienced a 5\% delinquency rate in 2009. Such a high rate indicates that the threat of foreclosure is not enough to deter default when house prices decline and the borrowers are deep under water. It is well known that default imposes substantial deadweight costs to both borrowers and lenders. Recent studies have also pointed out that foreclosures have negative social externalities. To remedy the weakness of FRM and save the deadweight costs of default, property index linked mortgages (PILM) have been proposed. These contracts link the balance and payment of the mortgage loan to a property index so that when property values decline, the loan is adjusted correspondingly. Consequently, the borrowers repay less and their incentives to default weaken.

This paper considers two different designs of PILM. The first design (PILM1) aims at controlling the current LTV ratio below a certain level, so the borrower will not be deep under water. The second design (PILM2) aims at compensating the borrower whenever the property is worth less than its purchase price. Despite the difference in loan adjustment schemes, they both require the lender to protect the borrower's equity in the mortgaged property.

We analyze the two PILM designs from the borrower's perspective. Under the baseline 
assumptions, both PILM designs reduce the borrower's propensity to default and increase his/her utility. The PILM lenders may achieve a higher expected present value of cash flows than the FRM lender, although we assume they do not charge for the equity protection they provide. This finding suggests that the PILMs could be Pareto improving relative to the FRM in the borrower-lender economy. The main reason behind this improvement is that the cost of loan adjustments is covered by the savings of foreclosure costs arising from the lower default probability. Comparing PILM1 with PILM2, we find that PILM2 has a lower default probability and derives higher welfare for both the borrower and lender.

We also analyze how the results change when alternative parameter values are assumed. The highlights of our findings are as follows. First, in all cases except when the PILM lenders charge a higher mortgage rate or the housing market is favorable to the borrowers, the PILM borrowers have lower default probabilities and higher welfare compared to the corresponding FRM borrower, but the PILM lenders' welfare could be higher or lower than that of the corresponding FRM lender.

Second, for a given contract, we find that a lower default probability is usually associated with higher borrower welfare. However, this relation does not hold in a few cases. For example, when the initial LTV is smaller (i.e., the down payment is increased), all borrowers have lower default probabilities and lower welfare compared to the baseline borrowers. A higher refinancing cost has a similar effect on PILM2.

Third, in the cases where the FRM borrower has a low default probability, the PILM lenders tend to have smaller, or even negative, welfare gains over the FRM lender. For example, when the ownership benefit increases or the borrower expects a bullish housing market, the FRM default probabilities drop considerably from the baseline value and both PILM lenders have smaller expected present values of cash flows compared to the FRM lender. In these cases, the borrower's propensity to default is low without equity protection, so the savings from foreclosure costs is insufficient to cover the cost of PILM loan adjustments, leading to lower expected present values of cash flows.

Lastly, since the contract-related parameters typically have opposite effects on the welfare of the borrower and lender, they can be used to adjust the welfare allocation between the borrower and lender. In our model, we can characterize a PILM1 contract by ( $\bar{\alpha}, \mathrm{RS} 1, \mathrm{PRE} 1)$ and a PILM2 contract by ( $\kappa$, RS2, PRE2). These contracts can be priced through these parameters.

Finally we point out some limitations of our model. We assume no basis risk so that the values of all properties are perfectly correlated with the underlying house price index. We also assume a constant non-storable income for simplicity. These two assumptions can be relaxed and incorporated into our model by adding a basis risk model (see Mei et al. [30]) and a stochastic income model (see Cocco et al. [13]), respectively. Our model can be further enriched by considering uncertainty in the borrower's lifespan.

Regarding mortgage decisions, we rule out some common practices in the real world, such as equity withdraw refinancing and loan modification. We also simplify our analysis by only allowing the PILM borrowers to refinance the loan into a FRM, and by prohibiting the borrowers 
from purchasing a property after default. These simplifications help us avoid complications while enable us focusing on comparing different mortgage designs.

Another strong assumption we make is that the housing market is exogenous to the borrower's choices and actions. This assumption may not hold when we consider a large number of borrowers. If PILMs do prevent default and default drags down property values during a recession, then PILMs do not only reduce default costs but also stabilize the housing market. Furthermore, PILMs may increase housing demand because households that do not want to bear the full house price risk and do not own property might consider homeownership through PILM financing. To resolve these issues we need an equilibrium model (see Kung [27]), which is beyond the scope of this paper.

\section{References}

[1] Adelino, M., K. Gerardi, and P. S. Willen (2013). Why Don't Lenders Renegotiate More Home Mortgages? Redefaults, Self-Cures and Securitization. Journal of Monetary Economics 60(7), 835-853.

[2] Ambrose, B. W. and R. J. Buttimer (2012). The Adjustable Balance Mortgage: Reducing the Value of the Put. Real Estate Eonomics 40(3), 536-565.

[3] Ambrose, B. W. and C. A. Capone (1996). Cost-Benefit Analysis of Single-Family Foreclosure Alternatives. Journal of Real Estate Finance and Economics 13(2), 105-120.

[4] Andritzky, J. R. (2014). Resolving Residential Mortgage Distress: Time to Modify? IMF Working Paper No. 14/226.

[5] Anenberg, E. and E. Kung (2014). Estimates of the Size and Source of Price Declines Due to Nearby Foreclosures. American Economic Review 104 (8), 2527-2551.

[6] Barth, J. R., T. Li, W. Lu, T. Phumiwasana, and G. Yago (2009). The Rise and Fall of the U.S. Mortgage and Credit Markets: A Comprehensive Analysis of the Market Meltdown. John Wiley \& Sons, Inc., Hoboken, New Jersey.

[7] Bhutta, N., J. Dokko, and H. Shan (2011). Consumer Ruthlessness and Mortgage Default During the 2007-2009 Housing Bust. SSRN Working Paper Series. Available at SSRN: http: //ssrn. com/abstract=1626969 or http://dx.doi.org/10.2139/ssrn.1626969.

[8] Bradley, M. G., A. C. Cutts, and W. Liu (2015). Strategic Mortgage Default: The Effect of Neighborhood Factors. Real Estate Economics 43(2), 271-299.

[9] Brueggeman, W. B. and J. D. Fisher (2006). Real Estate Finance and Investments (13th ed.). McGraw-Hill Irwin.

[10] Campbell, J. Y. and J. F. Cocco (2003). Household Risk Management and Optimal Mortgage Choice. Quarterly Journal of Economics 118(4), 1449-1494. 
[11] Campbell, J. Y. and J. F. Cocco (2015). A Model of Mortgage Default. Journal of Finance 70(4), 1495-1554.

[12] Campbell, J. Y., S. Giglio, and P. Pathak (2011). Forced Sales and House Prices. American Economic Review 101(5), 2108-2131.

[13] Cocco, J. F., F. J. Gomes, and P. J. Maenhout (2005). Consumption and Portfolio Choice over the Life Cycle. Review of Financial Studies 18(2), 491-533.

[14] Cotter, J., S. Gabriel, and R. Roll (2015). Can Housing Risk Be Diversified? A Cautionary Tale from the Housing Boom and Bust. Review of Financial Studies 28(3), 913-936.

[15] Deng, Y., J. M. Quigley, and R. V. Order (2000). Mortgage Terminations, Heterogeneity and The Exercise of Mortgage Options. Econometrica 68(2), 275-307.

[16] Elul, R., N. S. Souleles, S. Chomsisengphet, D. Glennon, and R. Hunt (2010). What "Trigers" Mortgage Default. American Economic Review: Papers \& Proceedings 100(2), 490-494.

[17] Foote, C. L., K. Gerardi, L. Goette, and P. S. Willen (2009). Reducing Foreclosures. Federal Reserve Bank of Boston, Public Policy Discussion Paper No.09-2.

[18] Foote, C. L., K. Gerardi, and P. S. Willen (2008). Negative Equity and Foreclosure: Theory and Evidence. Journal of Urban Economics 64 (2), 234-245.

[19] Gerardi, K., K. F. Herkenhoff, L. E. Ohanian, and P. S. Willen (2013). Unemployment, Negative Equity, and Strategic Default. SSRN Working Paper Series. Available at SSRN: http://ssrn. com/abstract=2293152 or http: //dx. doi .org/10.2139/ssrn . 2293152.

[20] Gerardi, K., E. Rosenblatt, P. S. Willen, and V. W. Yao (2015). Foreclosure Externalities: New Evidence. Journal of Urban Economics 87, 42-56.

[21] Goodman, L. S. (2010). Dimensioning the Housing Crisis. Financial Analysts Journal $66(3), 26-37$.

[22] Guiso, L., P. Sapienza, and L. Zingales (2013). The Determinants of Attitudes toward Strategic Default on Mortgages. Journal of Finance 68(4), 1473-1515.

[23] Hanewald, K. and M. Sherris (2011). House Price Risk Models for Banking and Insurance Applications. UNSW Australian School of Business Research Paper No.2011ACTL11. Available at SSRN: http://ssrn. com/abstract=1961402.

[24] Hellwig, M. F. (2009). Systemic Risk in the Financial Sector: An Analysis of the SubprimeMortgage FInancial Crisis. De Economist 157(2), 129-207. 
[25] Integrated Financial Engineering Inc. (2014). Actuarial Review of the Federal Housing Administration Mutual Mortgage Insurance Fund Forward Loans for Fiscal Year 2014. Integrated Financial Engineering Inc. U.S. Department of Housing and Urban Development http://portal.hud.gov/hudportal/HUD?src=/program_offices/housing/ rmra/oe/rpts/actr/actrmenu.

[26] Kau, J. B., D. C. Keenan, W. J. Muller, and J. F. Epperson (1995). The Valuation at Origination of Fixed-Rate Mortgages with Default and Prepayment. Journal of Real Estate Finance and Economics 11(1), 5-36.

[27] Kung, E. (2015). Mortgage Market Institutions and Housing Market Outcomes.

[28] Li, J. S.-H., M. R. Hardy, and K. S. Tan (2010). On Pricing and Hedging the No-Negativeequity Guarantee in Equity Release Mechanisms. Journal of Risk and Insurance 77(2), 499-522.

[29] Lo, A. W. (2012). Reading about the Financial Crisis: A Twenty-One-Book Review. Journal of Economic Literature 50(1), 151-178.

[30] Mei, Y., P. Boyle, and J. S.-H. Li (2017). Property Index Linked Mortgages: Pricing and Borrowers' Behaviour when Basis Risk is Present. Working paper.

[31] Mian, A. and A. Sufi (2014). House of Debt. The University of Chicago Press.

[32] Mian, A., A. Sufi, and F. Trebbi (2014). Foreclosures, House Prices, and the Real Economy. Fama-Miller Working Paper; Chicago Booth Research Paper No. 13-41; Kreisman Working Papers Series in Housing Law and Policy No. 6. Available at SSRN: http://ssrn.com/ abstract=1722195 or http://dx.doi.org/10.2139/ssrn.1722195.

[33] Qi, M. and X. Yang (2007). Loss Given Default of High Loan-to-Value Residential Mortgages. Office of the Comptroller of the Currency Economics Working Paper 2007-4.

[34] Shiller, R. J., R. M. Wojakowski, M. S. Ebrahim, and M. B. Shackleton (2013). Mitigating Financial Fragility with Continuous Workout Mortgages. Journal of Economic Behavior 8 Organization 85, 269-285.

[35] The Financial Crisis Inquiry Commission (2011). The Financial Crisis Inquiry Report. The Financial Crisis Inquiry Commission. Full report available at http://fcic. law. stanford. edu/report. 